Article

\title{
Modeling the Socioeconomic Metabolism of End-of-Life Tires Using Structural Equations: A Brazilian Case Study
}

\author{
Euclides Santos Bittencourt *, Cristiano Hora de Oliveira Fontes ${ }^{(1)}$ \\ Jorge Laureano Moya Rodriguez $\unrhd$, Salvador Ávila Filho $\unrhd$ and Adonias Magdiel Silva Ferreira \\ Graduate Program in Industrial Engineering, Universidade Federal da Bahia, Salvador 40210-630, Brazil; \\ cfontes@ufba.br (C.H.d.O.F.); jorgemoyar@gmail.com (J.L.M.R.); avilasalva@gmail.com (S.Á.F.); \\ adoniasmagdiel@ufba.br (A.M.S.F.) \\ * Correspondence: euclides.bittencourt@ufba.br
}

Received: 12 February 2020; Accepted: 28 February 2020; Published: 9 March 2020

check for updates

\begin{abstract}
Socioeconomic metabolism (SEM) is the exchange of materials and energy between society and the environment involving the social, economic and environmental sectors. In this paper, a boundary was defined between the economic (consumption) and environmental (waste recovery) limits in a city of 300,000 inhabitants in relation to the circulation (generation, reuse and disposal) of end-of-life tires (ELTs). The objective was to elaborate a theoretical structural model to evaluate the socioeconomic metabolism of waste (SEMw) by means of technical constructs (direct material flows (DMF), reverse material flows (RMF), socioeconomic environment (SEF) and sociodemographic factors (SDF)). Structural Equation Modeling (SEMm) was performed using Partial Least Squares Structural Equation Modeling (SmartPLS) software. The results obtained from the hypotheses show the causal relationships between the technical and social constructs and suggest guidelines for supporting the planning and management of urban solid waste in the collection and final disposal of ELTs. The processed information also contributes to the analysis of the city's socioeconomic scenarios in relation to the disposal of ELTs. One of the hypotheses tested (RMF have a direct effect on SEMw) shows the importance of managing ELTs through the correct final disposal of waste and recycling. SEMw was evaluated from the perception of the local society and it is concluded that it is possible to plan public policies to avoid the formation of waste inventory in the city.
\end{abstract}

Keywords: socioeconomic metabolism; structural equation modeling; end-of-life tires

\section{Introduction}

The world is experiencing one of the biggest sustainability crises that could jeopardize future generations. Urban waste is one of the aspects of this crisis that hampers the sustainability of the planet due to the behavior of production and consumption resulting from economic growth [1]. The consumption of economic agents and the degree of satiety of society drive the supply chain of materials and the development of products with a shorter life cycle [2]. Consequently, increasing waste without proper disposal threatens environmental sustainability [3].

Due to increased product consumption and waste generation, the use of effective tools for public solid waste management has been necessary to minimize environmental and public health impacts. These tools comprise regression analysis, Geographic Information System-Based methods, descriptive statistics and inferential statistics [4-7], among others. Developing countries have USWM (urban solid waste management) systems with different features and different levels of effectiveness [8-12]. The amount and type of USW collected in Central and Eastern European countries varies due to economic 
factors, income in particular. In Latin America, about 370,000 tons per day of municipal solid waste are generated and over $50 \%$ is disposed of in large urban centers and coastal municipalities with high tourist activity [8]. In Africa, only $31 \%$ of solid waste is collected in urban areas and most of it is not collected and disposed of properly due to the lack of appropriate infrastructure [13].

Groundwater contamination represents one of the main environmental impacts caused by solid waste (i.e., dissolved solids, leakage of leachate, etc.) [14-17]. The various types of waste generated but not collected are disposed of in remote locations, usually on public land or in small rivers which can cause the proliferation of endemic diseases. Among the various types of solid waste, ELTs (end-of-life tires) are a global problem due to their slow decomposition, high cost of reverse logistics (RL) and environmental impacts generated by disposal methods [18-22]. ELTs are widely used as an alternative fuel in cement kilns.

\begin{tabular}{|c|c|}
\hline \multicolumn{2}{|r|}{ Nomenclature } \\
\hline SEM & Socioeconomic Metabolism \\
\hline ELTs & End-of-Life Tires \\
\hline SEMw & Socioeconomic Metabolism of Waste \\
\hline UM & Urban Metabolism \\
\hline RL & Reverse Logistics \\
\hline $\mathrm{DMF}$ & Direct Material Flows \\
\hline $\mathrm{RMF}$ & Reverse Material Flows \\
\hline SEF & Socioeconomic Environment \\
\hline SDF & Sociodemographic Factors \\
\hline SmartPLS & Partial Least Squares Structural Equation Modeling \\
\hline PLS & Partial Least Square \\
\hline CB-SEM & Covariance-based structural equation Modeling \\
\hline CE & Circular Economy \\
\hline SEMm & Structural Equation Modeling \\
\hline SUTs & Supply and Use Tables \\
\hline MFA & Analyzed Material Flows \\
\hline TPB & Theory of Behavior and Planning \\
\hline MCDM & Multicriteria Method \\
\hline ISM & Interpretative Structural Modeling \\
\hline CLSC & Closed Loop Supply Chain \\
\hline USW & Urban Solid Waste \\
\hline EKC & Environmental Kuznets Curve \\
\hline PLS & Partial Least Square \\
\hline AVE & Extracted Variance \\
\hline IOA & Input and Output Analysis \\
\hline LCA & Life Cycle Analysis \\
\hline PGIRP & Integrated Pneumatic Waste Management Plan \\
\hline USWM & Urban Solid Waste Management \\
\hline NATI & National Association of Tire Industries \\
\hline EPR & Extended Producer Responsibility \\
\hline CONAMA & National Environmental Council \\
\hline
\end{tabular}

According to [23], 17 million tons of ELTs are generated per year worldwide. ELTs represent about $2 \%$ of the total waste generated by the global consumer society. In the US, about 257 million tires were discarded and 80 million were stocked in 2015. In the United Kingdom, 37 million tires from the transport system are discarded annually and it is estimated that this will increase by $63 \%$ by 2021 [24]. In Brazil, annual tire disposal is estimated at 300 tons with a total recycling rate of only $10 \%$ [25].

According to data from the National Association of Tire Industries (NATI), 62.6 million tire units were produced in 2016 [26]. The National Environmental Council (Brazil) Resolution (30 September 
2009) was regulated to control the impacts caused by ELTs and to determine the correct disposal of new tires sold in the aftermarket. A tire is considered ELT when it can no longer be used for circulation or reuse. ELTs are used as heating fuel for cement kilns, as secondary fuel in combined-cycle recovery boilers and coal-fired boilers. They are also used in oil shale gasification plants as a secondary raw material [27]. Even so, tire production is still much higher than the amount eliminated. The National Association of Tire Industries (NATI) sold 70.7 million units in 2016. Of these, $18.5 \%$ were exported, $18.2 \%$ were sold to automakers in the country and $63.4 \%$ were transferred to the aftermarket. Based on aftermarket sales, NATI presents the following distribution of used tire markets: (i) Not discarded by the consumer after replacement (36.9\%), (ii) Used and reconditioned tire markets (9.9\%), (iii) Sent to manufacturers (8.5\%), (iv) Landfills or "dumps" (10.9\%), (v) Lamination reprocessed for other uses (7.1\%) and (vi) Uncontrolled disposal (26.7\%).

Current works do not consider the socioeconomic and sociocultural context of countries and the environmentally specific solutions of each city, district and/or village in relation to the dynamics of material flows and waste streams [28]. Alternative, viable and appropriate methods to improve the efficiency of ELT management in developing countries are still lacking [23]. Therefore, special treatment is needed, incorporating integrated and environmentally effective strategies. The management of ELTs depends on the stakeholders (supplier and consumer), who exercise different roles and responsibilities, and is not just a commitment of municipal managers.

This work is related to the socioeconomic aspects of the reverse logistics of ELTs and presents a case study of a medium-sized city (Vitória da Conquista), located in the state of Bahia (Brazil). As a support, a model of structural equations was developed to verify the effect and influence of social constructs (SEF and SDF) related to the technical constructs (DMF and RMF), in order to evaluate the SEMw of ELTs. These constructs are part of the routine of socioeconomic relations between economic agents (supplier and consumer) [28], through the variables observed in the survey (Appendix A). The results reinforce that recycling is still the best alternative to mitigate the solid waste stock in the city.

\section{Literature Review}

SEM studies the biophysical part of the environment. Specifically, SEM is analogous to definitions of biological systems because it is subject to natural principles $[29,30]$. In short, the word metabolism refers to the totality of chemical reactions and the physical chemical changes that occur in living organisms [31]. The socioeconomic environment is a living organism that incurs social and economic events. The SEM proposes to account for exchanges between objects of biophysical origin within the limits of socioecological structures (SES) [32-36].

SEM is a dimension of industrial ecology that in recent decades has been investigating the impact of end-of-life materials and products on the environment [32,37]. In this type of investigation, techniques are adopted based on material mass balance (material input and output accounting methods) [38], life cycle analysis (LCA), supply and use tables (SUTs), and input and output material analysis (IOA) [39]. The SEF can be considered as a living organism and social or SEM analyzes the interactions between society and the environment by quantifying the set of material and energy flows produced by human actions through product consumption and economic activity [40,41]. Initially, SEM was named industrial metabolism [32] and later was characterized as social metabolism by [42]. The denomination SEM derives from studies and research by [41,43]. Urban metabolism (UM) or city metabolism is another concept that is determined by geographical boundary [36,44,45]. SEM is a way to quantify and study the impact of society on the urban environment. Measuring and seeking alternatives to reduce this impact is still a major challenge.

Ref. [46] investigated the UM system in Taipei city and examined the socioeconomic factors that led to an increase in cement and gravel consumption. More than $80 \%$ of the material used is applied primarily in construction and, later, improvements are made on the city's roads. Factors affecting metabolism have been identified including the slowdown in economic activity caused by the financial 
crisis in 2007 and 2008. [47] highlighted two urgent demands to improve the assessment of SEM: i) the need to adopt different measurement scales and ii) the need to address sustainable development issues.

Ref. [48] assessed energy and material flows within an urban system, considering social, community and family metabolism at scales ranging from global to local. The researchers collected information on system sustainability and the severity of urban problems and adopted linear models in cyclical processes and then models for analyzing energy and material flows, ecological footprints, inputs and outputs, and the characteristics of the system's ecological network. [39] analyzed the socio-environmental aspects of SEM through a broad spectrum of accounting structures and models. [49] assessed material flows in the Chinese economy (EW-MFA) and predicted the use of material resources to improve productivity.

Ref. [50] developed an SEMm to examine the relationship between urban household eating behavior and waste control in the city of Tehran. [51] developed an SEMm to explain the behavior of people who dispose of waste in open public spaces. [52] identified the effects of recycling efforts on subsequent resource utilization through SEMm based on partial least squares. The authors based their research on a database of indicators involving 356 Chinese citizens.

Ref. [53] conducted an analysis of housewives' attitudes and behaviors towards recycling, adopting Ajzen's Theory of Behavior and Planning (TPB) model and the application of the SEMm. The study concluded that there was a significant impact of housewives' attitudes on recycling dynamics. [54] elaborated an SEMm to analyze the factors that affect the implementation of waste management. [55] presented methods for assessing virgin tire production and ELTs disposal in India. In developed countries there are legal instruments such as EPR that require co-responsibility in RL and the final destination of ELTs. In India, a populous country with infrastructure problems, this mandatory management method has not yet been established. Two approaches, Interpretative Structural Modeling (ISM) and Multicriteria Metho (MCDM) were applied in this work [55]. Due to the fact that the sample comprises companies in a small region of southern India, biases caused by the personal character of managers' interpretation were identified. An approach based on SEM was applied together with ISM to solve sampling deficiencies. The study found that improved management of ELTs depends on a discard-oriented educational strategy.

The work of [55] proposes a theoretical framework to analyze the motivating factors in the management of ELTs for decision making through the MCDM and ISM. The main limitation is the elaboration of a database interrelated with driver behavior and management implications. In addition to these limitations pointed out by [55], the ISM does not directly consider the effects of SEF and SDF on the decision to buy new tires to properly dispose of ELTs. According to [56], the socioeconomic environment should be the place to assess environmental sustainability. [55] point out that modeling through structural equations can solve the intrinsic disadvantages of the ISM. No studies were found involving SEMm to evaluate SEMw specifically related to ELTs.

\section{Materials and Methods}

\subsection{Choice of the PLS Method}

In this research the Partial Least Square (PLS) method was adopted through the SmartPLS software for the structural model simulation [57]. Constructs are assessed through indicators and the variance between them determines the correlations [58]. These indicators are associated with models which including reflexive or formative constructs. In this research a model with reflexive constructs was adopted, where the direction of causality flows from the construct to the indicators and the perturbations (errors) are verified outside the structural model.

The literature highlights that PLS-SEM can be applied even when sample size is very small or even less than the number of observed variables [59-61], unlike the other approach used to estimate SEM (covariance-based structural equation modeling, CB-SEM). First of all, the PLS-SEM does not estimate all model parameters simultaneously. In addition, the PLS-SEM applies the bootstrapping procedure [62], widely applicable to quantify the uncertainty associated with a given statistical learning 
method. This approach involves repeated random sampling with replacement of the original sample and allows the estimated coefficients in PLS-SEM to be tested for their significance [63]. The PLS method has some advantages including that it works well with a small sample size and does not require data normality [64].

\subsection{Definition of Variables}

The metric $(\mathrm{M})$ and non-metric $(\mathrm{N} / \mathrm{M})$ constructs and indicators presented in Table 1 were defined according to literature information on socioeconomic metabolism [30,39,65-68]. Direct materials (direct material flows, DMF) comprise the tires required by society (DMF_3_Demand) to meet their needs (DMF_4_Requests). New tires replenish the aftermarket by forming a large supply chain (DMF_1_ Supplier Network) [28,69-71]. This chain is managed by the National Association of Tire Industries (NATI) which serves the interests of tire producers and importers (DMF_7_ Marketing). Supply chains are comprised of large tire wholesalers/retailers and reuse companies representing the entire city supply market (DMF_2_Supply Network). Reverse materials (reverse material flows, RMF) comprise the waste stock that is disposed of by society after use $[23,28,72-75]$. ELTs are collected (RM_1_Collect) through specific urban planning (RMF_2_Urban planning) which establishes the voluntary and scheduled waste collection plan (ELTs) in the warehouse (RMF_3_Accumulation) until final disposal (RMF_5_ Final Destination). ELTs are sent for reuse (RMF_7_ Retreading), or are recycled (RMF_6_ Recycling) and processed at co-processing plants. Externalities caused by the foreign market and the world economic environment (RMF_4_Externalities) must be considered. Stakeholder training (RMF_10_ Team training) and forecasting studies (RMF_8_Forecasts) are conducted to improve urban solid waste management planning (RMF_9_ Waste Management).

The social constructs were ordered by SDF and SEF [76,77]. Social factors were introduced into the model to verify the correlation index with the SEMw. The indicators were selected based on similar studies which adopt sociodemographic factors (variables) (SDF_1_ Family Composition, SDF_2_ Professional Activity, SDF_3_ Per capita income, SDF_4_ Schooling, SDF_5_ Population density, SDF_6_Age and SDF_7_ Urban Space) and socioeconomic factors (SEF_2_ Municipal Policy, SEF_3_Basic Sanitation and SEF_6_ Local Culture). Socioeconomic factors (SEF_1_Investment, SEF_4_ GDP (aggregate income) and SEF_5_Consumption) are variables often adopted in economic analysis.

The socioeconomic waste metabolism construct comprises the set of material flow measurement methods (SEMw_2_MFA, SEMw_5_LCA, SEMw_6_ Recycling and SEMw_7_ IOA _). The SEMw_1_Investment, SEMw_3_CE and SEMw_4_Economic value _ indicators involve monetary measurement (\$). 
Table 1. List of Constructs and Indicators.

\begin{tabular}{|c|c|c|c|c|}
\hline Construct & Indicator & Description & $\begin{array}{c}\text { Metric (M)/ } \\
\text { Non-Metric (N/M) }\end{array}$ & References \\
\hline \multirow{7}{*}{$\begin{array}{l}\text { Direct Material } \\
\text { Flows } \\
\text { DMF }\end{array}$} & DMF_1 & Supplier Network (t) & M & \multirow{7}{*}[28,69-71]{} \\
\hline & DMF_2 & Supply Network (t) & M & \\
\hline & DMF_3 & Demand $(\mathrm{t})$ & M & \\
\hline & DMF_4 & Requests $(\mathrm{t})$ & M & \\
\hline & DMF_5 & Location & $\mathrm{N} / \mathrm{M}$ & \\
\hline & DMF_6 & Regulation & $\mathrm{N} / \mathrm{M}$ & \\
\hline & DMF_7 & Marketing & $\mathrm{N} / \mathrm{M}$ & \\
\hline \multirow{10}{*}{$\begin{array}{c}\text { Reverse Material } \\
\text { Flows } \\
\text { RMF }\end{array}$} & RMF_1 & Collect (t) & $\mathrm{M}$ & \multirow{10}{*}[13,23,69,71-75]{} \\
\hline & RMF_2 & Urban planning & $\mathrm{N} / \mathrm{M}$ & \\
\hline & RMF_3 & Accumulation $(\mathrm{t})$ & $\mathrm{M}$ & \\
\hline & RMF_4 & Externalities $(\mathrm{t})$ & M & \\
\hline & RMF_5 & Final Destination $(\mathrm{t})$ & M & \\
\hline & RMF_6 & Recycling $(t)$ & M & \\
\hline & RMF_7 & Retreading $(\mathrm{t})$ & M & \\
\hline & RMF_8 & Forecasts $(\mathrm{t})$ & M & \\
\hline & RMF_9 & Waste Management (\$) & M & \\
\hline & RMF_10 & Team training $(\$)$ & M & \\
\hline \multirow{7}{*}{$\begin{array}{c}\text { Sociodemographic } \\
\text { Factors } \\
\text { SDF }\end{array}$} & SDF_1 & Family Composition & $\mathrm{N} / \mathrm{M}$ & \multirow{7}{*}[76,77]{} \\
\hline & SDF_2 & Professional Activity (\$) & M & \\
\hline & SDF_3 & $\begin{array}{l}\text { Per capita income } \\
\text { (\$/inhabitants) }\end{array}$ & M & \\
\hline & SDF_4 & $\begin{array}{l}\text { Schooling } \\
\text { (\$/students) }\end{array}$ & M & \\
\hline & SDF_5 & $\begin{array}{l}\text { Population density } \\
\text { (Inhabitants } / \mathrm{Km}^{2} \text { ) }\end{array}$ & M & \\
\hline & SDF_6 & Age (years) & M & \\
\hline & SDF_7 & Urban Space $\left(\mathrm{Km}^{2}\right)$ & M & \\
\hline \multirow{6}{*}{$\begin{array}{l}\text { Socioeconomic } \\
\text { Environment } \\
\text { SEF }\end{array}$} & SEF_1 & Investment (\$) & M & \multirow{6}{*}[76,77]{} \\
\hline & SEF_2 & Municipal Policy & $\mathrm{N} / \mathrm{M}$ & \\
\hline & SEF_3 & Basic Sanitation & $\mathrm{N} / \mathrm{M}$ & \\
\hline & SEF_4 & GDP (aggregate income) (\$) & $\mathrm{M}$ & \\
\hline & SEF_5 & Consumption (\$) & M & \\
\hline & SEF_6 & Local Culture & $\mathrm{N} / \mathrm{M}$ & \\
\hline \multirow{8}{*}{$\begin{array}{l}\text { Socioeconomic } \\
\text { Metabolism of } \\
\text { Waste } \\
\text { SEMw }\end{array}$} & SEMw_1 & Environmental Cost (\$) & M & \multirow{8}{*}[30,39,65-68]{} \\
\hline & SEMw_2 & MFA (t) & M & \\
\hline & SEMw_3 & $\mathrm{CE}$ & $\mathrm{N} / \mathrm{M}$ & \\
\hline & SEMw_4 & Economic value (\$) & M & \\
\hline & SEMw_5 & LCA $(t)$ & M & \\
\hline & SEMw_6 & Mass Balance (t) & M & \\
\hline & SEMw_7 & $\operatorname{IOA}(\mathrm{t})$ & M & \\
\hline & SEMw_8 & Metabolic Rate (t/years) & M & \\
\hline
\end{tabular}

The inclusion or exclusion of a given indicator does not affect the measurement model and, consequently, the structural model [78].

\subsection{Sampling}

Development of a data collection instrument (questionnaire) and estimation of minimum sample size (number of respondents) was done through the use of the software GPower (3.0.10). This software allows the estimation of statistical power and sample size through some statistical tests. The questionnaire was answered based on the Likert scale $[79,80]$ with scores for each question from 1 ("not important") to 5 ("very important"). The composition of sample was defined considering the following items:

(i) Audience profile:

- Definition of the number of indicators. 
(ii) Definition of the power of the statistical test and the effect of exogenous variables (f2). [58,81] recommend the use of test power 0.80 and the average effect size (f2) equal to 0.15 . Heterogeneous composition with random search of respondents from five segments of society (Civil servant, employee in the private sector, tire and correlated entrepreneurs, university teaching staff and students). Most factory direct employees and manufacturing specialists, including RL professionals, were not selected to avoid bias in technical issues (indicators).

\subsection{Measurement and Structural Analysis}

Definition of the theoretical model and test through indicators. These indicators are the result of survey questions. The indicators were validated in the confirmatory exploratory analysis if they had a factor load between 0.708 to 0.95 [58].

Simulation and analysis of the measurement model was done according to the following tests [82]:

- Internal consistency.

- Convergent validity.

- Validity of the discriminant of the measurement model.

The structural model simulation applies the bootstrap and blindfolding procedures to verify its predictive capacity $[83,84]$. The bootstrap approach consists of obtaining different datasets from the original sample to assess the level of uncertainty level (effect size f2) associated with structural model estimates. In this paper, the bootstrap approach was developed using 5000 subsamples from the original replacement sample. The blindfolding approach measures the Predictive Relevance Q2 and the effect Q2 or impact of exogenous constructs on endogenous constructs [63]. The adopted criteria are presented in Tables 2 and 3.

Table 2. Measurement model analysis criteria [58].

\begin{tabular}{cccc}
\hline Objective & Measurement & Criteria & References \\
\hline Indicator & Factorial Load & $>0.708^{*}$ & \\
& Cronbach's Alpha & AC $>0.7^{* *}$ & [85] \\
Internal Consistency & Composite Reliability & CR $>0.7$ & \\
rho_A & rho_A $>0.7^{* * *}$ & \\
Convergent validity & Average variance extracted (AVE) & AVE $>0.5$ & Cross Loads \\
Discriminant validity & Fornell and Larcker Criteria & Factorial Load (AVE) & {$[86,87]$} \\
\hline
\end{tabular}

Note: * Indicators with factorial loads above 0.95 indicate that items are redundant, reducing construct validity [88].

** Ideal Cronbach's Alpha values should be between 0.70 and 0.95. Cronbach's Alpha tends to underestimate reliability when sample size is small $(<100)$. The ideal method is to adopt the composite reliability measure. ${ }^{* * *}$ The coefficient rho_A returns a mean value between Cronbach's Alpha (AC) and Composite Reliability (CR) [89].

Table 3. Structural model analysis criteria $[78,90]$.

\begin{tabular}{|c|c|c|c|}
\hline Objective & $\begin{array}{l}\text { Measurement } \\
\text { Parameter }\end{array}$ & Criteria & References \\
\hline $\begin{array}{l}\text { Evaluate the variance of } \\
\text { endogenous constructs } \\
\text { explained by all exogenous } \\
\text { constructs }\end{array}$ & $\begin{array}{l}\text { Pearson's coefficient of } \\
\text { determination }\left(\mathrm{R}^{2}\right)\end{array}$ & Between 0 and $1^{*}$ & [91] \\
\hline $\begin{array}{l}\text { Evaluate the effect of the } \\
\text { exogenous construct when it is } \\
\text { excluded from the model }\end{array}$ & $\begin{array}{l}\text { Effect Size or Cohen } \\
\text { Indicator }\left(f^{2}\right)\end{array}$ & $\begin{array}{c}0.02 \text { — small effect } \\
0.15 \text { - average effect } \\
0.35 \text { - big effect }\end{array}$ & \\
\hline $\begin{array}{l}\text { Evaluate the predictive power } \\
\text { of originally observed values }\end{array}$ & $\begin{array}{l}\text { Predictive Validity or } \\
\text { Stone-Geisser Indicator } \\
\text { or Cross-Validity } \\
\text { Redundancy }\left(\mathrm{O}^{2}\right)\end{array}$ & $\begin{array}{c}0.02 \text { —small relevance } \\
0.15 \text {-average relevance } \\
0.35 \text { - great relevance }\end{array}$ & [85] \\
\hline Assess causal relationships & Path coefficient & $\begin{array}{l}\text { The ideal } t_{\text {value }} \text { value must be above } \\
1.96 \text { and the path coefficient must be } \\
\text { non-zero at a significance level of } 5 \% \text {. }\end{array}$ & \\
\hline
\end{tabular}

Note: * It is difficult to provide practical rules for acceptable $\mathrm{R}^{2}$ values. Usually parsimonious models (with high $\mathrm{R}^{2}$ values and fewer exogenous constructs) are prioritized [85,89]. 


\subsection{Modeling Hypothesis}

The general hypothesis for proposal of a structural equations model is that the technical constructs (DMF and RMF) and social constructs (SEF and SDF) have a strong correlation with SEMw. Hypothesis $\mathrm{H} 2, \mathrm{H} 3, \mathrm{H} 4$ and $\mathrm{H} 5$ (continuous arrows) are assumed to directly affect SEF and indirectly SEMw, while hypothesis H1, H6 and H8 (discontinuous arrows) directly affect SEMw (Figure 1).

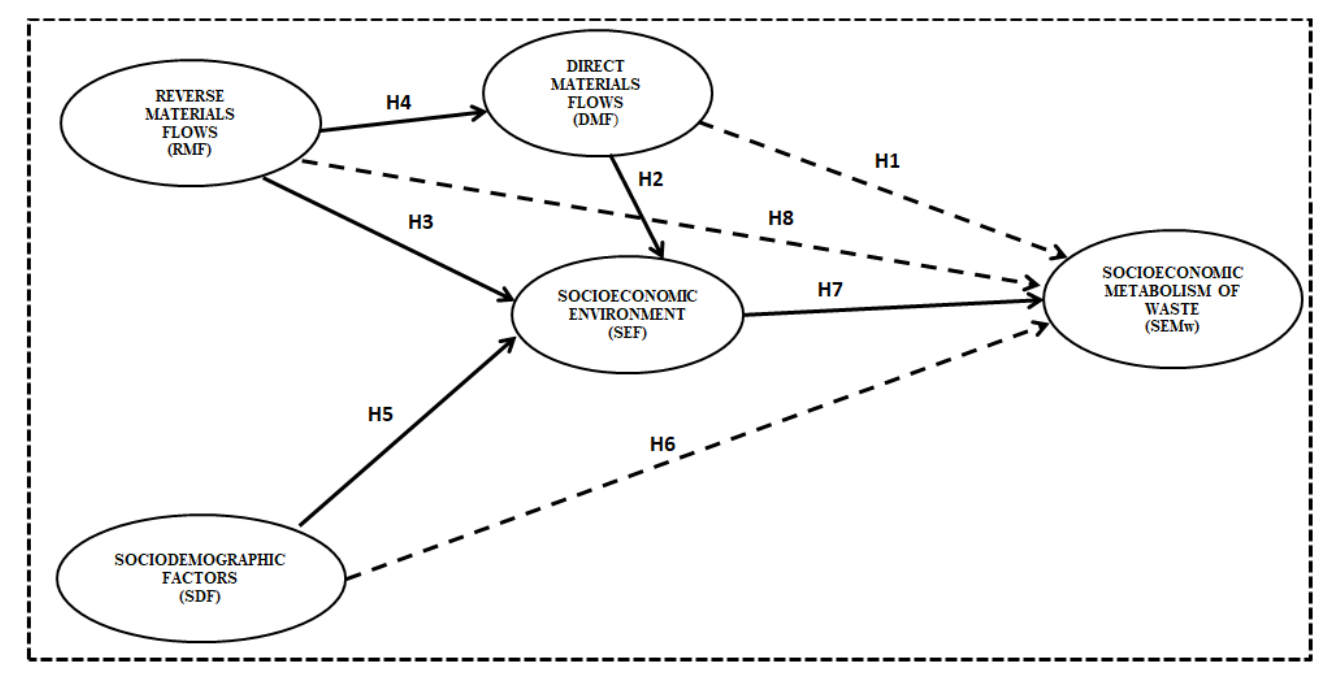

Figure 1. Theoretical model to assess SEMw.

DMF refer to the new tire inflows acquired by different companies and the stock of tires in circulation [92]. In the case study, there are nine wholesale companies, 150 retail companies supplying about 1000 tons/year, and about 100,000 tons of tires are in circulation in the city.

RMF are the reverse flows of ELTs [93,94] that are reused by business logistics [94,95]. In the case study, public solid waste management annually collects about 300 tons of ELTs and disposal can only be done properly by about 250 RL companies (Reciclanip) who generally sell ELTs for burning in co-processing furnaces. About 50 tons of better-condition ELTs are reused for 22 used tire reformers. ELTs not recovered by RL or unknown streams of ELTs are allocated to remote parts of the city, landfill or even the riverbed. A model that relates behavioral phenomena and the technical aspects of logistics can minimize the amount of ELTs that are discarded by the consumer society.

SDF refer to a combination of social and demographic factors related to diverse characteristics of individuals (age, sex, sexual orientation, race, religion, income, marital status, birth rate, mortality rate, average family size, inheritance, education, medical history) and are able to identify/recognize homogeneous social groups according to these characteristics [77]. SEF is related to the socioeconomic environment or economic factors, such as the sociological, economic, educational and professional aspects that enable the classification of an individual or group of individuals in a particular socioeconomic group [76]. In the socioeconomic environment there are direct and indirect relations of exchange of goods, consumption of materials and disposal of waste. Indicators of material circulation through disposal to the environment provide information for assessing socioeconomic metabolism [96].

\subsection{Justification for the Hypothesis}

The hypothesis that DMF has an effect on SEMw is an axiom tested in structural equation modeling, because in addition to income level, there are non-economic relationships that determine the level of DMF in the environment [97]. These non-economic relationships are associated with market imperfections, uncertainties in the behavior of economic agents and the dynamics of the macroeconomic environment [98]. Economic and non-economic relationships offer limits to the increase in new tire 
DMF in Brazilian cities, suggesting that not all new tires will be sold and used by society, despite marketing pressures.

Figure 2 shows the Environmental Kuznets Curve (EKC) associated with the relationship between per capita income and the amount of DMF (tires sold in Brazil), from 2010 to 2015 [99]. The EKC presents two inflection points of the DMF in the 5 year interval, 72.90 million tires (2011) and 74.30 million tires (2013), showing a reduction in the DMFs as per capita income increases over the time. In 2012, the EKC has the lowest amount of DMF produced in the Brazilian tire supply chain (67.90 million tires).

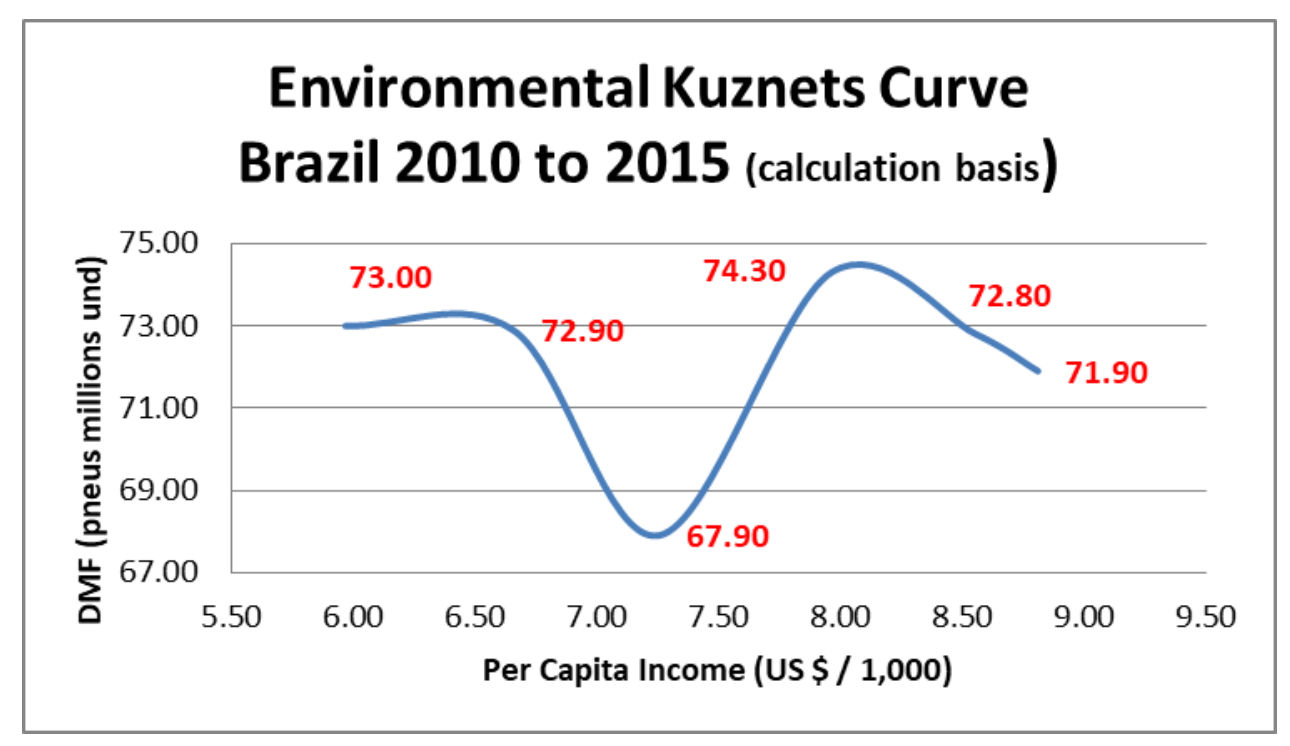

Figure 2. Environmental Kuznets Curve.

According to [100] this argument is based on the hypothesis of the EKC which evaluates the relationship between economic growth (economic production) and environmental pollution.

There are currently other cultural ideologies related to the purchasing decision and conscious and sustainable consumption habits of society based on CE principles [101]. Tire consumption does not have linear behavior. The number of new tires entering the Brazilian economy is greater than demand because manufacturing companies (members of the National Association of Tire Industries) have chosen to import new tires from China rather than source locally, mainly due to the price instability of synthetic rubber. There are anti-dumping practices against importing tires for commercial vehicles, trucks, buses, motorcycles and even bicycles [102]. From the above considerations, the following hypothesis (See Table 4) was considered for model formulation:

\section{H1: DMF have a direct effect on SEMw.}

The effect of DMF on the SEF and the production of a specific good has been investigated [103,104], as well as the correlation of these flows with waste accumulation [105,106]. According to [107,108], DMF have a direct effect in the formation of large waste inventories and impact on SEF. Two-decade studies of the EKC between material consumption and pollutant generation prove an inverse relationship between the economic environment and urban waste [109]. In this case, the increase in the direct flow of tires depends on income but also on price policy due to the scarcity of raw materials, imports, taxes, public policies, road conditions and consumer behavior, among other socioeconomic variables [110,111]. Thus, the following hypothesis was formulated:

H2: DMF have a direct effect on SEF.

Studies about RL show that improving the waste management system can minimize environmental impacts [74,112]. Socioeconomic variables such as the fraction of waste collected by individual action and population density are relevant in the waste management plan. It is noteworthy that part of the 
RMF is directly represented by RL and the other part is related to sociodemographic and socioeconomic aspects [107]. In the case of ELTs, RMF represent the recovery of end-of-life products (materials) for reuse or beneficiation [75]. Recycling is one of the most commonly used techniques in RMF to reduce pollution, reduce landfill use and conserve natural resources [113]. According to [49], recycling is an important technique for reducing the impacts of the economic activity. [114] points out that the behavior of recycling depends on a variety of behavioral, sociodemographic and socioeconomic factors (number of collection sites, distance to deposition points, absence of incentives and information). Thus, the following hypothesis is proposed:

\section{H3: RMF have a direct effect SEF.}

The relationship between DMF and RMF is perfectly understandable for integrating a city's material flows [73,92]. According to [115] this relationship has often been discussed by CE theorists, mainly to assess economic gains from RL material utilization and environmental impact minimization. Some studies show that the integration between DMF and RMF is represented by the closed loop supply chain (CLSC) [74]. ELTs, for example, are stocked, collected and destined for various purposes, mainly for energy reuse [92]. There is a conceptual relationship between the number of vehicles and the amount of ELTs [55,74]. Thus, these assumptions support the following hypothesis:

\section{H4: RMF have a direct effect on DMF.}

Studies on selective collection and recycling have good results when SDF are considered in the SEF [116]. According to [77], sociodemographic variables contribute to explain the generation of recyclable materials and, therefore, exert direct effect on SEF. According to [56,117], forecasts of household waste generation are effective when family size and disposal method are considered. [76] show that the housing characteristics and household location influences solid waste disposal. Among SDF, some authors $[77,118]$ consider the average household size, the proportion of people with higher education, the amount of housing, the purchasing power, the percentage of people employed in agriculture and the sex ratio to be important. [119] verified through structural equations the direct effects of SDF on the SEF and the direct effects of solid waste generation on the urban household scale. Income per capita, population density and unemployment rate (unemployed) are efficient and effective variables for predicting waste scenarios [100]. [120] developed models for predicting the generation and diversion of urban solid waste (USW) according to demographic and socioeconomic aspects. Thus the following hypothesis is proposed:

H5: SDF have a direct effect on SEF.

According to [100], SDF are associated with municipal solid waste generation and influence consumer behavior to a certain extent. The disassociation is related to the saturation of consumption or the dynamics of sociodemographic and/or socioeconomic factors such as regionalism, local culture, generational change and unilateral decisions of economic agents [121]. According to (Knickmeyer, 2019), population density positively affects waste generation as the retail market operates in densely populated urban areas and produces more waste. However, the implementation of a tariff system or some collection mechanism for waste generation causes a reduction in the consumption of densely populated areas [122], confirming the hypothesis of the EKC [123]. Per capita income is unable to identify the concentration points of consumption of goods (tires) in the economy. In Brazil, consumption occurs more intensely from the second semester of the fiscal year when extra income is added to the economy through the refund of the 13th salary, which improves the exchange mechanism and strengthens the circulating environment. The decision to purchase a tire is not linear and waste generation (ELT) depends on the social and environmental behavior of city residents. Decisions depend on economic policy and the opportunities suggested by the supply chain (marketing). Thus, the following hypothesis was formulated to verify if there is a direct relationship between sociodemographic factors and SEMw:

H6: SDF have a direct effect on SEMw. 
Ref. [124] state that SEF has a direct effect on waste generation. According to [76], SEF lead families to use a specific solid waste disposal system. [96] adopted macroeconomic indicators to assess socioeconomic metabolism and [107] explain that the amount of direct inflows in the economy significantly exceeds the direct inflows of households resulting in material stocks and impacts on SEMw. [125] estimated the potential effects of economic policies on material flows in SEMw. Therefore, the following hypothesis are proposed:

H7: SEF have a direct effect on SEMw.

RMF represents the recovery of end-of-life products (materials) for reuse [75]. RMF are measured by material flow accounting methods $[50,119]$. RMF has an economic value defined by the market for materials used in the burning of cement kilns. ELTs are waste that is difficult to dispose of and has a high cost of implementing reverse logistics. Despite this, specific public policies are needed to control threats to public health [101]. ELTs and RMF are highly complex inert materials for municipal solid waste management.

Applying ELTs as a fuel is one of the best alternatives for eliminating tire inventories in cities, as well as improving the $\mathrm{CO}^{2}$ emission rates of cement manufacturing companies that use these residues for clinker burning and agglutination [126]. The collection of ELTs depends on specific procedures because besides technical aspects, socioeconomic factors are present in the dynamics of urban solid waste management. The ELT management model depends on laws, normative instructions and actions that involve subjective aspects of society. These models include the principles of CE, economic instruments for valuing materials, the tax system and extended producer responsibility. The management of ELTs in developed countries requires society's knowledge of integrated programs that consider environmental sustainability agendas, storage, systematic and consistent approaches to ELT market regulation and the implementation of methods to address the problem of inventory in cities [28].

In this study RMF are being hypothetically tested on SEMw as part of causal relationships. In hypothesis H1, the first order endogenous DMF construct is the mediator (or moderating) variable of the second order SEMw endogenous construct. In order to test the causal relationships of the RMF exogenous construct, even with the redundancy that the residues impact the environment, it was necessary to verify the impact of RMF on the SEMw endogenous construct.

According to this, the following hypothesis is proposed:

H8: RMF have a direct effect on SEMw.

Table 4. Summary of hypotheses.

\begin{tabular}{ccc}
\hline Hypothesis & Description & References \\
\hline H1 & DMF have a direct effect on SEMw. & {$[97,98,100-102]$} \\
H2 & DMF have a direct effect on SEF. & {$[39,55,74,100,103,105,107-111]$} \\
H3 & RMF have a direct effect $S E F$. & {$[49,74,75,107,112-114]$} \\
H4 & H4 - RMF have a direct effect on DMF. & {$[73,74,92,115]$} \\
H5 & SDF have a direct effect on SEF. & {$[56,76,77,100,116-120]$} \\
H6 & SDF have a direct effect on SEMw. & {$[100,121-123,127]$} \\
H7 & SEF have a direct effect on SEMw. & {$[76,96,107,124,125]$} \\
H8 & RMF have a direct effect on SEMw. & {$[50,75,101,113,126,128]$} \\
\hline
\end{tabular}

\section{Results and Discussion}

\subsection{Demographic Profile}

Table 5 presents the demographic profile of the population (aged 25 to 54 years) considered in the study. Male and female participation is balanced and shows that $40 \%$ of respondents have an income between 10 and 25 times the minimum wage (minimum wage is $\$ 260$ ). It is also observed 
that $20 \%$ of respondents have an income above 25 times the minimum wage. These people own cars, are consumers of parts and accessories and, above all, tires. Of the other respondents, about $50 \%$ are workers and $60 \%$ are students or university graduates.

Table 5. Case study demographic profile of the of the participants in survey.

\begin{tabular}{|c|c|c|c|c|c|}
\hline \multicolumn{6}{|c|}{ Demographic Characteristics of City (Case Study) Respondents } \\
\hline Demography & Frequency & $\%$ & Demography & Frequency & $\%$ \\
\hline Age (years) & & & $\begin{array}{c}\text { Professional } \\
\text { Activity }\end{array}$ & & \\
\hline$<24$ & 11 & 11.11 & Civil servant & 25 & 25.25 \\
\hline 25 to 34 & 32 & 32.32 & Private Employee & 26 & 26.26 \\
\hline 35 to 44 & 40 & 40.40 & Businessman & 7 & 7.07 \\
\hline 45 to 54 & 12 & 12.12 & College professor & 20 & 20.20 \\
\hline$>55$ & 4 & 4.04 & Student & 21 & 21.21 \\
\hline Sex & & & Education Level & & \\
\hline Male & 51 & 51.52 & Elementary School & 11 & 11.11 \\
\hline Female & 43 & 43.43 & High school & 31 & 31.31 \\
\hline \multirow[t]{2}{*}{ Other } & 5 & 5.05 & University student & 30 & 30.30 \\
\hline & & & Graduate & 27 & 27.27 \\
\hline \multicolumn{6}{|l|}{ Income } \\
\hline$<2.5$ Minimum Wage $(\mathrm{MW})$ & 16 & 16.16 & & & \\
\hline $2.5 \mathrm{MW}$ to $10.5 \mathrm{MW}$ & 23 & 23.23 & & & \\
\hline 10.5 MW to $25.5 \mathrm{MW}$ & 40 & 40.40 & & & \\
\hline $25.5 \mathrm{MW}$ to $50.5 \mathrm{MW}$ & 17 & 17.17 & & & \\
\hline $50.5 \mathrm{MW}$ to $105.5 \mathrm{MW}$ & 3 & 3.03 & & & \\
\hline 105.5 MW to $505.5 \mathrm{MW}$ & - & - & & & \\
\hline$>505.5 \mathrm{MW}$ & - & - & & & \\
\hline
\end{tabular}

\subsection{Exploratory Factor Analysis}

Figure 3 shows the indicators confirmed through exploratory analysis. The indicators excluded from the analysis are presented in Table 6. These indicators have a factor load below 0.708 [58]. Among these, three indicators (RMF_4,SEMw_4 and SEMw_8) with factorial load above 0.5 were excluded because they did not show good results in the reliability test. SEM-PLS prioritizes indicators according to their individual reliability [129].

Table 6. Indicators excluded from structural equation modeling.

\begin{tabular}{cccc}
\hline Construct & Indicator & Description & Factorial Load \\
\hline \multirow{2}{*}{ Direct Material Flows } & DMF_1 & Supplier Network & 0.133 \\
(DMF) & DMF_6 & Regulation & 0.430 \\
& DMF_7 & Marketing & 0.451 \\
\hline \multirow{2}{*}{ Reverse Material Flows } & RMF_2 & Urban planning & 0.173 \\
(RMF) & RMF_3 & Accumulation & 0.209 \\
& RMF_4 & Externalities & 0.528 \\
& RMF_7 & Retreading & 0.077 \\
Sociodemographic Factors & RMF_10 & Team training & 0.045 \\
(SDF) & SDF_1 & Family Composition & 0.068 \\
& SDF_2 & Professional Activity & 0.194 \\
& SDF_6 & Age & 0.206 \\
Socioeconomic Environment & SDF_7 & Urban Space & 0.121 \\
(SEF) & SEF_1 & Investment & 0.637 \\
\hline Socioeconomic Metabolism & SEMw_3 & Environmental Cost & 0.495 \\
of Waste & SEMw_4 & Economic value & $\mathbf{0 . 5 8 0}$ \\
(SEMw) & SEMw_8 & Metabolic Rate & $\mathbf{0 . 5 5 2}$ \\
\hline
\end{tabular}




\subsection{Measurement Model Analysis}

In Table 7 the measures of internal consistency (Cronbach's Alpha, CR and rho_A > 0.7) and convergent validity (AVE $>0.5)$ are shown. The results show that the measurement model is suitable for validation of the structural model [58]. These results depend on the random errors that may compromise the accuracy of direct measurement of indicators and indirect constructs. Indicators with a factorial load below 0.708 are acceptable in exploratory surveys when categorical scales are used $[58,130]$.

The RMF_8 (Forecasts) indicator was maintained in the measurement model, although the factorial load value of 0.493 is below 0.708 (see criteria Table 2). This indicator is important in the theoretical model because it favors solid waste planning and management for decision making regarding the waste collection strategy. According to [130] there are situations in confirmatory factor analysis that rather than automatically eliminating indicators when external load is below 0.70 , one should carefully examine the effects of indicator exclusion on composite reliability as well as the construct's content validity. In this work, the exclusion of the RMF_8 indicator (Forecasts) did not affect the reliability of the RMF construct measured by Cronbach's Alpha indicator which had an increase of $0.52 \%$, and did not compromise the CR (increased 1.53\%) and rho_A (decreased 2.17\%) of the measurement model. This decision that violates the factor load factor less than 0.708 was also maintained for the indicators RMF_1, RMF_9,SEF_2,SEF_5,SEF_6,SEMw_1 and SEMw_5 which have a factor load between 0.6 and 0.7 and are consistent in the theoretical model. These indicators positively influence the quality of the internal consistency measures of the constructs. The composite reliability, which shows the level of association between constructs and construct indicators, ranged from 0.799 to 0.877 , while Cronbach's Alpha values ranged from 0.759 to 0.816 (above the minimum of 0.7 as recommended by [131]). The average variance extracted (AVE) showing the amount of total variance in the indicators represented by the construct ranged from 0.512 to 0.689 (above the recommended minimum of 0.5 by [58]).

Table 7. Measurement model test results with validated indicators.

\begin{tabular}{|c|c|c|c|c|c|c|c|c|}
\hline Construct & Items & Description & Load & $\begin{array}{l}\text { Cronbach's } \\
\text { Alpha }\end{array}$ & rho_A & $\mathrm{CR}^{1}$ & $\operatorname{AVE}^{2}$ & Note \\
\hline \multirow{4}{*}{$\begin{array}{l}\text { Direct Material } \\
\text { Flows } \\
\text { (DMF) }\end{array}$} & DMF_2 & Supply Network & 0.733 & \multirow{4}{*}{0.816} & \multirow{4}{*}{0.844} & \multirow{4}{*}{0.877} & \multirow{4}{*}{0.641} & \\
\hline & DMF_3 & Demand & 0.765 & & & & & \\
\hline & DMF_4 & Requests & 0.860 & & & & & \\
\hline & DMF_5 & Location & 0.837 & & & & & \\
\hline \multirow{5}{*}{$\begin{array}{c}\text { Reverse Material } \\
\text { Flows } \\
\text { (RMF) }\end{array}$} & RMF_1 & Collect & 0.673 & \multirow{5}{*}{0.759} & \multirow{5}{*}{0.804} & \multirow{5}{*}{0.799} & \multirow{5}{*}{0.512} & Excluding the RMF-8 indicator, \\
\hline & RMF_5 & Final Destination & 0.887 & & & & & reliability: \\
\hline & RMF_6 & Recycling & 0.797 & & & & & Cronbach's Alpha $=0.759$ \\
\hline & RMF_8 & Forecasts & 0.493 & & & & & (decreased $0.52 \%$ ) \\
\hline & RMF_9 & $\begin{array}{l}\text { Waste } \\
\text { Management }\end{array}$ & 0.664 & & & & & $\begin{array}{c}C R=0.763 \text { (increased } 1.53 \%) \\
\text { rho_A }=0.782 \text { (decreased } 2.17 \%)\end{array}$ \\
\hline \multirow{3}{*}{$\begin{array}{c}\text { Sociodemographic } \\
\text { Factors } \\
\text { (SDF) }\end{array}$} & SDF_3 & Per capita income & 0.787 & \multirow{3}{*}{0.782} & \multirow{3}{*}{0.874} & \multirow{3}{*}{0.869} & \multirow{3}{*}{0.689} & \\
\hline & SDF_4 & Schooling & 0.905 & & & & & \\
\hline & SDF_5 & $\begin{array}{l}\text { Population } \\
\text { density }\end{array}$ & 0.794 & & & & & \\
\hline \multirow{5}{*}{$\begin{array}{l}\text { Socioeconomic } \\
\text { Environment } \\
\text { (SEF) }\end{array}$} & SEF_2 & Municipal Policy & 0.659 & \multirow{5}{*}{0.780} & \multirow{5}{*}{0.807} & \multirow{5}{*}{0.851} & \multirow{5}{*}{0.537} & \\
\hline & SEF_3 & Basic Sanitation & 0.779 & & & & & \\
\hline & SEF_4 & $\begin{array}{l}\text { GDP (aggregate } \\
\text { income) }\end{array}$ & 0.878 & & & & & \\
\hline & SEF_5 & Consumption & 0.649 & & & & & \\
\hline & SEF_6 & Local Culture & 0.670 & & & & & \\
\hline \multirow{5}{*}{$\begin{array}{l}\text { Socioeconomic } \\
\text { Metabolism of } \\
\text { Wastes } \\
\text { (SEMw) }\end{array}$} & SEMw_1 & $\begin{array}{c}\text { Environmental } \\
\text { Cost }\end{array}$ & 0.669 & \multirow{5}{*}{0.793} & \multirow{5}{*}{0.803} & \multirow{5}{*}{0.858} & \multirow{5}{*}{0.55} & \\
\hline & SEMw_2 & MFA & 0.820 & & & & & \\
\hline & SEMw_5 & LCA & 0.610 & & & & & \\
\hline & SEMw_6 & Mass Balance & 0.788 & & & & & \\
\hline & SEMw_7 & IOA & 0.798 & & & & & \\
\hline
\end{tabular}

Table 8 shows the result of discriminant validity through the Fornell and Larcker criterion [87]. The validity of the discriminant is evaluated by comparing the correlations between the constructs and the square root of the extracted variance for a construct. The square root values of variances extracted by 
constructs on the diagonal of the matrix are larger than the correlations below the diagonal, indicating adequate discriminant validity. This denotes that each construct alone captures the phenomena not represented by other constructs in the model.

Table 8. Result of the discriminant validity (Fornell and Lacker Criterion).

\begin{tabular}{cccccc}
\hline & DMF & RMF & SDF & SEF & SEMw \\
\hline DMF & $\mathbf{0 . 8 0 0}$ & & & & \\
RMF & 0.591 & $\mathbf{0 . 7 1 5}$ & & & \\
SDF & 0.336 & 0.360 & $\mathbf{0 . 8 3 0}$ & & \\
SEF & 0.694 & 0.697 & 0.417 & $\mathbf{0 . 7 3 2}$ & \\
SEMw & 0.549 & 0.658 & 0.345 & 0.662 & $\mathbf{0 . 7 4 2}$ \\
\hline
\end{tabular}

The diagonal is the square root of AVE of the latent variables and is the highest in any column or row.

\subsection{Analysis of Hypotheses and Path Coefficients ( $\beta$ )}

Figure 3 shows hypothesis $\mathrm{H} 1$ to $\mathrm{H} 8$ through the path coefficients $(\beta)$ that represent the possible structural relationships of interdependence of the model. Positive or negative values represent the direct and indirect cause-effect relationships allowed in the hypothesis. In the case of hypothesis H1 ( $\beta=-0.119)$, DMF have a direct and negative influence on SEMw because consumers' decisions do not depend solely on their income level. Hypothesis $\mathrm{H} 1$ was refuted due to the practice of relationships in the tire market that do not follow the predictability of the economic environment. The reverse of hypothesis $\mathrm{H} 1$ is also due to: (a) income elasticity, that is, as income increases, people tend to want more environmental quality; (b) changes in the dynamics of production and consumption; (c) consumer specialization that becomes more stringent due to an improvement in the level of environmental education; (d) awareness of the consequences of economic activity on the environment and (e) hidden material flows (imports) that are not accounted for in the economy.

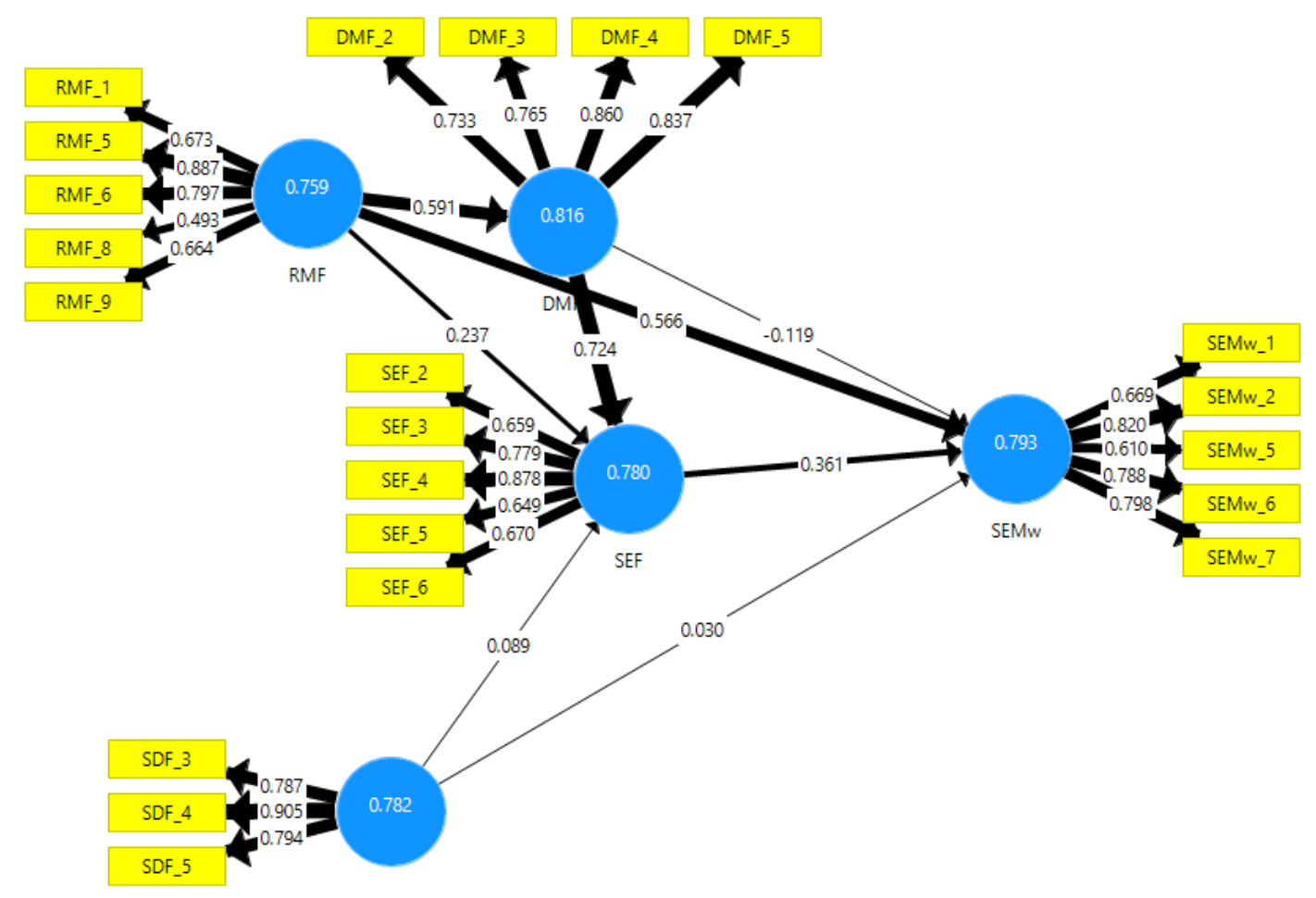

Figure 3. Path model, external loads and structural coefficients. 
These decisions, in turn, depend on the economic environment (SEF) as shown in hypothesis $\mathrm{H} 2$ ( $\beta=0.724)$ which was accepted by the model. This hypothesis establishes that everything produced from DMF has a direct effect on SEF and indirect on SEMw because the behavior of economic agents and consumer rationality determine the purchase of tires, despite the fact that income is rising in the economy and has an effect on production.

Decisions to produce more tires depend on socioeconomic factors as well as sociodemographic factors and, above all, public policies on solid waste management in the city. Not all DMF produced will be waste and measured in SEMw. This means that income tends to be inelastic because consumers' decisions about goods diminish. This phenomenon is more noticeable in developed countries [100].

In hypothesis H3 $(\beta=0.237)$, the ELTs collected by RL are reused from SEF, even with the technical limitation of urban solid waste management resources. This is ratified by hypothesis $\mathrm{H} 4(\beta=0.591)$ since RMF positively influence the DMF construct. This means that in hypothesis H8 $(\beta=0.566)$, the RMF directly influence the SEMw measurement. A real example is ETLs collected in the city (case study analyzed) that add value when they are recycled and introduced for business purposes. The integration of these DMF and RMF streams is strong when there is good solid waste management [74].

Hypothesis H5 $(\beta=0.089)$ shows that the SDF construct has a slight direct and positive influence on SEF. This shows that it is possible to identify a smooth relationship between sociodemographic phenomena and the economic environment, unlike hypothesis H6 $(\beta=0.030)$ which was refuted due to a weak effect on SEMw.

In hypothesis H6, SDF have a direct effect on SEMw was rejected. Despite the small population increase, the level of education and per capita income, SDF have a direct effect on SEF which implies that there is direct relationship between social behavior and material consumption. The result of hypothesis $\mathrm{H} 6$ is justified because consumption decisions only take place in the economic environment in which supply and demand factors are present. Directly relating SDF to SEMw is an assumption. Traditional SDF variables (population increase, age, education level, per capita income) do not cause the SEMw rate to increase or decrease. These variables depend on the cultural environment of the society involved in the consumption of materials (tires).

In hypothesis H5, SDF have a small influence on SEMw but this does not necessarily occur elsewhere. SEMw depends on socioeconomic decisions combined with the dynamics of DMF and RMF and the sociodemographic profile of society. The intensity of the flows represented by the path coefficients depends on the correlations between the independent (exogenous constructs represented by RMF and SDF) and dependent (endogenous constructs represented by DMF, SEF and SEMw) variables. The structural model expresses the behavior of the city at a given moment in social life, where economic agents are not affected by SDF and their own decisions.

The SEF construct brings together the technical and socioeconomic interactions of the model. SEF are a mediating construct that concentrates socioeconomic information for measurement in SEMw.

According to hypothesis H7 $(\beta=0.361)$, the SEF construct has a strong influence on SEMw. This construct is the branch of technical and social interactions that influence the dynamics of SEM. It is understood that social interventions due to population increase, age and per capita income level are dynamics that affect SEMw variability. Cronbach's alpha values (interior of the circles) are above 0.7, which denotes a good measure of internal consistency of the indicators in relation to exogenous and endogenous constructs.

\subsection{Analysis of the Structural Model}

Table 9 shows the results of the structural model tests (explained variance $\mathrm{R}^{2}$ and predictive relevance $\mathrm{Q}^{2}$ ) according to the hypotheses proposed in the conceptual model. The SEF construct explains $61.3 \%\left(R^{2}=0.613\right)$ of the SEMw variance, according to the criteria in Table 3. In addition, the RMF and SDF constructs respectively explain $84.9 \%\left(R^{2}=0.849\right)$ of the SEF variance and the RMF construct explains $35.0 \%\left(R^{2}=0.350\right)$ of the variance of the SEF construct. The model hypothesis 
testing after the bootstrap procedure rejected hypothesis $\mathrm{H} 1$ and $\mathrm{H} 6$, therefore, these hypotheses were not supported.

This procedure provides guidance for deciding whether data is too far from normally distributed (the higher $t_{v a l u e}$, the better the $p_{\text {value }}$ probability). Then, the effect size $\mathrm{f}^{2}$ of the explained variance $\mathrm{R}^{2}$ was verified with the inclusion and exclusion of exogenous constructs. Hypothesis $\mathrm{H} 2$ has a very strong direct effect $\mathrm{f}^{2}=2.152$ in the SEF construct, followed by hypothesis $\mathrm{H} 3$ with a medium effect $\mathrm{f}^{2}=0.212$, $\mathrm{H} 4$ with a medium effect $\mathrm{f}^{2}=0.538$ and hypothesis $\mathrm{H} 5$ with a small effect $\mathrm{f}^{2}=0.040$. Hypothesis $\mathrm{H} 7$ had a very strong direct effect of $\mathrm{f}^{2}=1.711$, while hypothesis $\mathrm{H} 8$ also had a direct strong effect on the SEMw of $\mathrm{f}^{2}=0.320$.

The result of the predictive relevance $\mathrm{Q}^{2}$ is obtained using the blindfolding procedure, which is analogous to the $\mathrm{R}^{2}$ evaluation. The inclusion or exclusion of exogenous constructs determines the effect size $\mathrm{q}^{2}$ on predictive relevance $\mathrm{Q}^{2}$. The effect size $\mathrm{q}^{2}$ from hypothesis $\mathrm{H} 2$ and $\mathrm{H} 4$ show respectively the values of $\mathrm{q}^{2}=0.279$ and $\mathrm{q}^{2}=0.236$. Hypothesis $\mathrm{H} 3$ and $\mathrm{H} 5$ showed the effect size $q^{2}$ of predictive relevance between small to medium respectively, $q^{2}=0.030$ and $q^{2}=0.020$. Both hypotheses discreetly reflect additional information about the quality of estimates of the socioeconomic environment (SEF) PLS path model. In contrast, the effect size of $\mathrm{q}^{2}=0.107$ on the predictive relevance of hypothesis $\mathrm{H} 8$ is strong for estimating the reverse material flows construct (RMF) in measuring the socioeconomic metabolism of SEMw residues.

This paper assumes a significance level of $5 \%(p<0.05)$ for $\mathrm{t}$-value greater than 1.96 . Hypothesis $\mathrm{H} 2, \mathrm{H} 3, \mathrm{H} 4$ and H8 have a strong significance level, respectively, $\mathrm{t}_{\mathrm{value}}=14.498, \mathrm{t}_{\mathrm{value}}=4.370$, $\mathrm{t}_{\text {value }}=7.419$ and $\mathrm{t}_{\mathrm{value}}=6.558$. While hypothesis $\mathrm{H} 5$ and $\mathrm{H} 7$ have an average statistical significance with $t_{\text {value }}=2.097$ and, $t_{\text {value }}=2.452$. Hypothesis $\mathrm{H} 1$ and $\mathrm{H} 6$ had lower statistical significance $t_{\text {value }}<1.96$ and were rejected in the modeling.

Table 9. Result of the structural model.

\begin{tabular}{|c|c|c|c|c|c|c|c|c|c|}
\hline & \multirow[t]{2}{*}{ Hypothesis } & \multirow{2}{*}{$\mathbf{R}^{2}$} & Std & Std & \multirow{2}{*}[t-\text{Value}{}^{*}]{} & \multirow{2}{*}{ Decision } & \multirow{2}{*}{$\mathbf{f}^{2}$} & \multirow{2}{*}{$\mathrm{Q}^{2}$} & \multirow{2}{*}{$q^{2}$} \\
\hline & & & Beta & Error & & & & & \\
\hline H1 & DMF -> SEMw & 0.613 & -0.119 & 0.123 & 0.968 & Not Supported & -0.008 & 0.292 & -0.006 \\
\hline $\mathrm{H} 2$ & DMF -> SEF & 0.849 & 0.724 & 0.050 & 14.498 & Supported & 2.152 & 0.409 & 0.279 \\
\hline $\mathrm{H} 3$ & $\mathrm{RMF}->\mathrm{SEF}$ & 0.849 & 0.237 & 0.054 & 4.370 & Supported & 0.212 & 0.409 & 0.030 \\
\hline $\mathrm{H} 4$ & $\mathrm{RMF}->\mathrm{DMF}$ & 0.350 & 0.591 & 0.080 & 7.419 & Supported & 0.538 & 0.191 & 0.236 \\
\hline H5 & $\mathrm{SDF}->\mathrm{SEF}$ & 0.849 & 0.089 & 0.042 & 2.097 & Supported & 0.040 & 0.409 & 0.010 \\
\hline H6 & SDF $->$ SEMw & 0.613 & 0.030 & 0.089 & 0.338 & Not Supported & 0.313 & 0.292 & -0.003 \\
\hline H7 & SEF $->$ SEMw & 0.848 & 0.361 & 0.147 & 2.452 & Supported & 1.711 & 0.292 & 0.079 \\
\hline H8 & RMF ->SEMw & 0.613 & 0.566 & 0.086 & 6.558 & Supported & 0.320 & 0.292 & 0.107 \\
\hline
\end{tabular}

statistical significance $(p<0.05)$.

\subsection{Analysis of the Structural Model}

The structural model is shown in Figure 4, after removing hypothesis H1 and H6 that were not supported in the bootstrap procedure and smoothly changing the path coefficients of the accepted hypotheses (H2, H3, H4, H5 and H7). In the SEF construct, all socioeconomic interactions that will be measured in the SEMw construct occur. The SEMw endogenous construct is an index formed by exogenous and endogenous first order constructs. The structural model is presented through the following equations:

$$
\begin{gathered}
D M F=0.589 R M F+\zeta_{1} \\
S E F=0.665 R M F+0.091 S D F+\zeta_{2} \\
S E M w=0.750 R M F+0.024 S D F+\zeta_{3}
\end{gathered}
$$




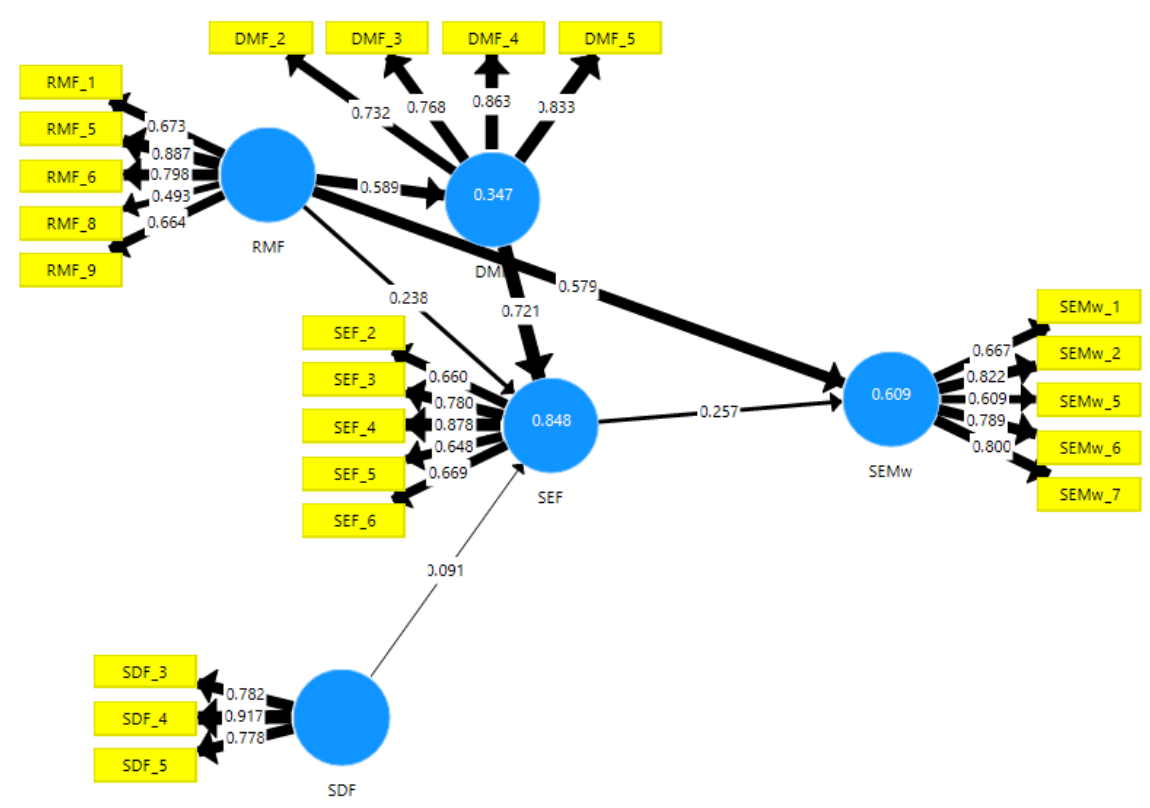

Figure 4. Structural model after tests and adjustments.

For the simulation of Equations (2) and (3) (mainly Equation (3) which estimates the SEM of residues, SEM_w), it is possible to relativize or deduce the RMF and SDF values through metric and/or monetary quantities. The SDF construct is not measured directly by known metric units, but it is possible to establish a proportionality relationship between the SDF_3 (per capita income), SDF_4 (education) and SDF_5 (population density) indicators to transform them into mass (Kg) or monetary (\$) quantity. The RMF can be measured directly by weighing the waste collected in reverse logistics.

These equations are generated directly from the model (see Figure 4) to estimate the SEM of waste index explained by the exogenous constructs as shown by [85]. SEMw is the index resulting from the amount of reverse material flows and socioeconomic factors. RMF have a coefficient of 0.750 $(75 \%)$ associated with dynamic materials that are discarded by society, while SDF have a coefficient of $0.024(2.4 \%)$. The effect of sociodemographic factors (SDF) is practically discrete in determining the socioeconomic metabolism of waste. This statement can be confirmed in the work of $[77,100,116,119]$.

The SEMw index is determined as a function of RMF, but the influence of SDF, although small, should be considered. Increasing DMF in the economic environment (SEF) is not necessarily linked to SDF because other factors are associated with consumption such as education and income. Eventually, the increase in SDF may be a determining factor in SEMw if the economy is in full use of the factors of production and the quality of life of economic agents (individuals and companies) has also improved. The high SEMw index means that there is a lot of material entering the economy which requires policies of greater reuse in society by the RMF. On the other hand, the lower SEMw index may mean that society is being more controlled in relation to generation of ELTs at source, that endogenous infrastructure factors have improved the life cycle of tires in circulation or that other accessibility policies and/or mass transportation are achieving satisfactory environmental results.

\section{Model Construction as a Tool for Waste Management}

The information obtained from the structural model can support the prioritization of actions within the scope of solid waste management, establishing an order of preference in the preparation of procedures to support reverse logistics until the final destination. The results reflect the opinion of the local society by degree of importance, according to the sampling plan.

Figure 5 shows the scores ( $t$-student) of the indicators and constructs obtained after applying the bootstrap. The scores are highlighted by the e-sankey technique. The factorial loads of the indicators and the path coefficients (Hypothesis " $\beta$ ") of the constructs were replaced by the scores linked to 
arrows (less or wider) that represent the importance hierarchy of the indicators in relation to the impact on the constructs.

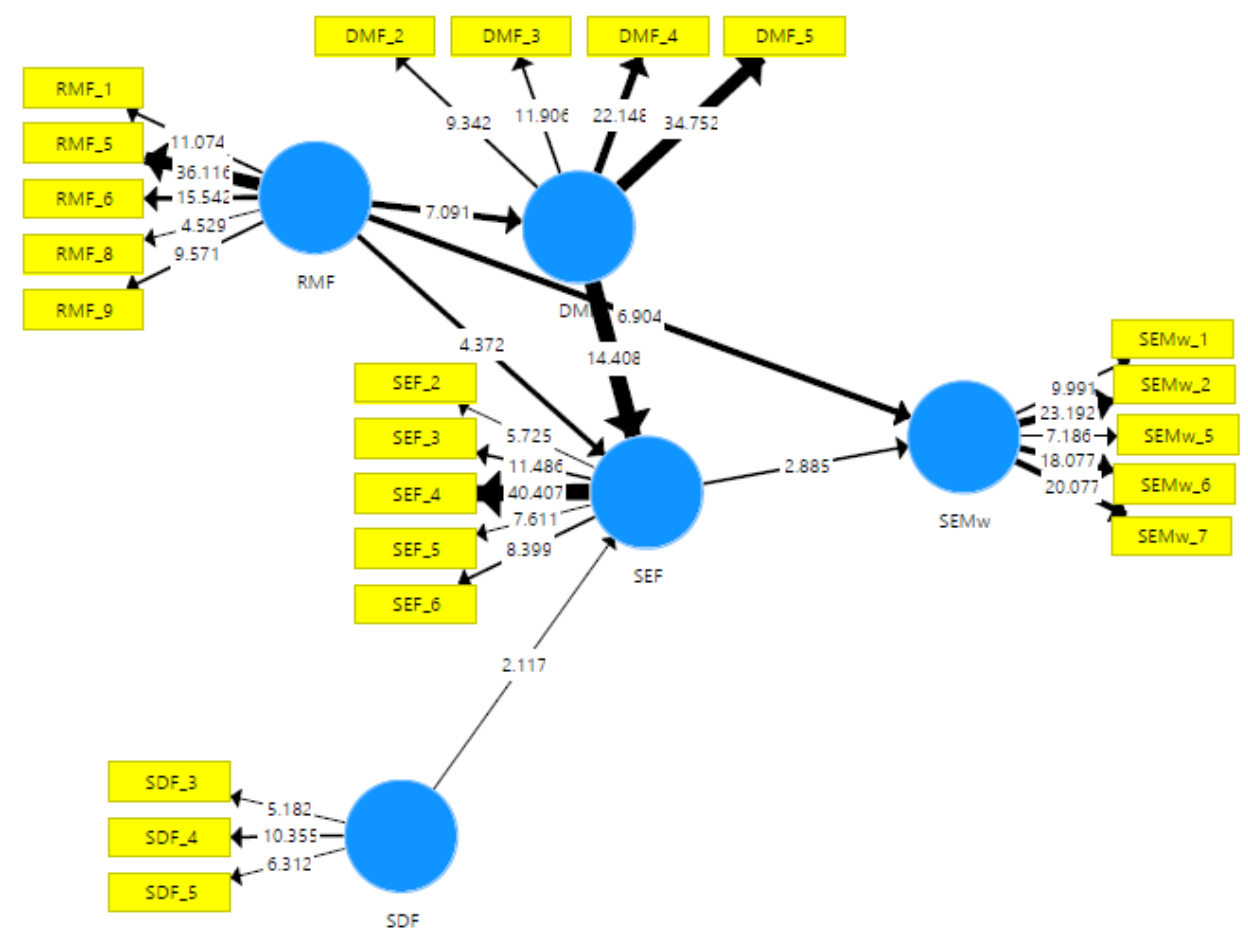

Figure 5. Scores (t-student) of the indicators and constructs.

Table 10 shows the percentage values or the participation of indicators in the indirect measurement of the constructs by score ( $\left.t_{\text {value }}\right)$ of the external model. These values are relativized (percentages). The higher the ( $\left.t_{\text {value }}\right)$, the better the significance ( $\left.p_{\text {value }}\right)$.

In the external structural model, the DMF_ 5 indicator has a $44 \%$ share in the DMF construct. This indicator is associated with the location of tire suppliers that have significant weight in the local economy material flows $[107,108]$. In the case of the city of Vitória da Conquista, the road logistics mode is privileged by the largest highway in the country (BR-116). In this structural equation model, the DMF construct strongly influences the SEF construct, which implies a 55\% dynamic of the SEF_4 (Local GDP) indicator, 16\% of the SEF_3 (basic sanitation) indicator, 13\% of the SEF_6 (culture of local economic agents) indicator, 10\% of the indicator SEF_5 (consumption) and $8 \%$ of the indicator SEF_2 (municipal policy). Therefore, the city's GDP is more representative for RMF formation. The socioeconomic environment (SEF) construct depends on the balance of these indicators.

Socioeconomic activities, in turn, are also influenced by sociodemographic factors (SDF). The level of education represented by the SDF_ 4 indicator accounts for $47 \%$ of the SDF construct. The SEMw index also depends on the direct measurements of the indicators, regardless of the influence of the RMF and SEF constructs. The indicators SEMw_1 (environmental cost), SEMw_2 (MFA), SEMw_6 (mass balance) and SEMw_7 (IOA) constitute accounting methods for valuation of materials and energy flows and participate with $13 \%, 30 \%, 22 \%$ and $26 \%$, respectively. These indicators were identified in the literature review as the most frequently used material accounting methods to assess socioeconomic metabolism. 
Table 10. Percentage distribution of external model by construct.

\begin{tabular}{|c|c|c|c|c|c|}
\hline Construct & Items & Description & Loadings & t_Value & $\%$ \\
\hline \multirow{4}{*}{$\begin{array}{l}\text { Direct Material Flows } \\
\text { (DMF) }\end{array}$} & DMF_2 & Supply Network & 0.736 & 9.342 & 12 \\
\hline & DMF_3 & Demand & 0.766 & 11.906 & 15 \\
\hline & DMF_4 & Requests & 0.859 & 22.148 & 28 \\
\hline & DMF_5 & Location & 0.836 & 34.752 & 44 \\
\hline & $\Sigma$ & & 3.197 & 78.148 & 100 \\
\hline \multirow{5}{*}{$\begin{array}{l}\text { Reverse Material Flows } \\
\text { (RMF) }\end{array}$} & RMF_1 & Collect & 0.698 & 11.074 & 14 \\
\hline & RMF_5 & Final Destination & 0.876 & 36.116 & 47 \\
\hline & RMF_6 & Recycling & 0.783 & 15.542 & 20 \\
\hline & RMF_8 & Forecasts & 0.485 & 4.529 & 6 \\
\hline & RMF_9 & Waste Management & 0.658 & 9.571 & 12 \\
\hline \multirow{4}{*}{$\begin{array}{l}\text { Sociodemographic } \\
\text { Factors } \\
\text { (SDF) }\end{array}$} & $\Sigma$ & & 3.500 & 76.832 & 100 \\
\hline & SDF_3 & Per capita income & 0.788 & 5.182 & 24 \\
\hline & SDF_4 & Schooling & 0.904 & 10.355 & 47 \\
\hline & SDF_5 & Population density & 0.795 & 6.312 & 29 \\
\hline \multirow{6}{*}{$\begin{array}{l}\text { Socioeconomic } \\
\text { Environment } \\
\quad(\text { SEF })\end{array}$} & $\Sigma$ & & 2.487 & 21.849 & 100 \\
\hline & SEF_2 & Municipal Policy & 0.659 & 5.725 & 8 \\
\hline & SEF_3 & Basic Sanitation & 0.776 & 11.486 & 16 \\
\hline & SEF_4 & $\begin{array}{l}\text { GDP (aggregate } \\
\text { income) }\end{array}$ & 0.876 & 40.407 & 55 \\
\hline & SEF_5 & Consumption & 0.654 & 7.611 & 10 \\
\hline & SEF_6 & Local Culture & 0.672 & 8.399 & 11 \\
\hline \multirow{6}{*}{$\begin{array}{c}\text { Socioeconomic } \\
\text { Metabolism of Wastes } \\
(\text { SEMw) }\end{array}$} & $\Sigma$ & & 3.637 & 73.628 & 100 \\
\hline & SEMw_1 & Environmental Cost & 0.712 & 10.047 & 13 \\
\hline & SEMw_2 & MFA & 0.788 & 23.318 & 30 \\
\hline & SEMw_5 & LCA & 0.646 & 6.961 & 9 \\
\hline & SEMw_6 & Mass Balance & 0.752 & 17.398 & 22 \\
\hline & SEMw_7 & IOA & 0.775 & 19.851 & 26 \\
\hline & $\Sigma$ & & 3.673 & 77.575 & 100 \\
\hline
\end{tabular}

The RMF construct has a significant influence on SEMw because the indicators are strongly correlated. The RMF_5 indicator (final destination), which represents the correct destination of ELTs for corporate reuse, participates, preferably, with $47 \%$ in the indirect measurement of the construct. The RMF_6 (recycling) indicator participates in $20 \%$ of the construct and this business activity adds value in the processing of ELTs. The RMF_6 indicator (collection) participates with 20\% of the construct, adds value to the RL of ELTs and its effectiveness minimizes health epidemics. The RMF_9 (waste management) indicator has a $12 \%$ share in the RMF construct. Waste management also has the executive task of organizing, deciding and controlling a city's reverse material flow system. The RMF_8 (forecast) indicator participates with $6 \%$ and is the most discrete in the construct. Waste forecasting is a tool to support ELT inventory planning in the city.

Table 11 shows the three iterations of the internal structural coefficient measurement model that were simulated in the bootstrap procedure. The iterations confirmed that direct material flows (DMF) have a score of $38 \%$ of strong influence on the socioeconomic environment (SEF). The other relationships are due to reverse material flows (RMF) and sociodemographic factors (SDF), which respectively influence $11 \%$ and $6 \%$ in the socioeconomic environment (SEF). RMF participate with 19\% in DMF and $18 \%$ in SEMw. 
Table 11. Internal model bootstrap result.

\begin{tabular}{cccccccc}
\hline \multirow{2}{*}{ Hypothesis } & \multirow{3}{*}{} & \multicolumn{2}{c}{ 1st Iteration } & \multicolumn{2}{c}{ 2nd Iteration } & \multicolumn{2}{c}{ 3rd Iteration } \\
\cline { 3 - 8 } & & $\boldsymbol{t}$ _Value & $\boldsymbol{\%}$ & $\boldsymbol{t}$ _Value & $\boldsymbol{\%}$ & $\boldsymbol{t}$ _Value & $\boldsymbol{\%}$ \\
\hline H2 DMF -> SEF & 0.721 & 14.408 & $\mathbf{3 8}$ & 14.343 & $\mathbf{3 8}$ & 14.460 & $\mathbf{3 8}$ \\
H3 RMF -> SEF & 0.238 & 4.372 & $\mathbf{1 1}$ & 4.355 & $\mathbf{1 1}$ & 4.369 & $\mathbf{1 1}$ \\
H4 RMF -> DMF & 0.589 & 7.091 & $\mathbf{1 9}$ & 7.182 & $\mathbf{1 9}$ & 7.194 & $\mathbf{1 9}$ \\
H5 SDF -> SEF & 0.091 & 2.117 & $\mathbf{6}$ & 2.141 & $\mathbf{6}$ & 2.107 & $\mathbf{6}$ \\
H7 SEF -> SEMw & 0.257 & 2.885 & $\mathbf{8}$ & 2.902 & $\mathbf{8}$ & 2.914 & $\mathbf{8}$ \\
H8 RMF -> SEMw & 0.579 & 6.904 & $\mathbf{1 8}$ & 6.973 & $\mathbf{1 8}$ & 6.942 & $\mathbf{1 8}$ \\
& & 37.77 & 100 & 37.90 & 100 & 37.99 & 100 \\
\hline
\end{tabular}

\section{Conclusions}

The structural model developed can be analyzed based on two dimensions. The first is related to the theoretical implications of modeling the phenomenon and the second refers to the implications of managing ELTs in a medium-sized city.

(i) Theoretical implications of modeling the phenomenon

In the literature, SEM is measured using classical methods that assess the amount of mass flow and energy entering and leaving the economic system, without considering other subjective factors or the socioeconomic context of the place. The results of the mass and energy balances are usually adjusted by supply tables for life cycle analysis and/or material flow analysis. This work comprises an innovative approach, through the modeling of structural equations, capable of relating objective (metric) and subjective (non-metric) variables. The result of the structural equation modeling (SEMm) confirmed $70 \%$ of the hypotheses presented in the theoretical framework to evaluate the socioeconomic metabolism of waste (SEMw).

The model rejected hypothesis $\mathrm{H} 1$ and $\mathrm{H} 6$ for not having a correlation in SEMw and only recognizes the importance of these hypotheses in the direct measure of SEF. The indicators adopted in SEF (municipal policy, SEF_2, Sanitary Conditions, SEF_3, GDP, SEF_4, Consumption, SEF_5 and Local Culture, SEF_6) are representative and strengthen the indirect measurement of SEMw. DMF is not measured directly in SEMw because not all material produced will be consumed due to limitations in long-term income per capita, as shown in the environmental EKC.

The sociodemographic profile of the sample also contributed to rejection of hypothesis $\mathrm{H} 1$ and $\mathrm{H} 6$. SDF is not directly measured in SEMw due to social distortions in relation to the level of environmental education, population density and level of income per capita. This phenomenon can also be proven through the analysis of the structural model, which discusses the effect size $\left(\mathrm{f}^{2}\right)$ and the predictive relevance $\left(\mathrm{q}^{2}\right)$ of the exogenous constructs (RMF and SDF) shown in Table 9. The RMF and SDF are independent constructs that explain the structural model and are more representative in the structural relationship with the SEF.

Therefore, it was essential to consider SEF. The $\mathrm{R}^{2}(0.849)$ associated with hypothesis H2, H3, $\mathrm{H} 5$ explains the importance of the exogenous constructs RMF and SDF on the endogenous construct SEF and the value of $\mathrm{R}^{2}(0.848)$ of hypothesis $\mathrm{H} 7$ explains the importance of the endogenous construct SEF on the endogenous construct SEMw. The value of $\mathrm{R}^{2}(0.613)$ related to hypothesis H8 shows that the RMF construct explains only $61.3 \%$ of the SEMw endogenous construct. This result is consistent since the model considers the uncertainties associated with reverse logistics and the low level of environmental education in society, aided by the urban cleaning program. These explanations clarify the behavior of the proposed structural model.

(ii) Implications for ELT management

The correct final disposal of ELTs depends on the planning and management of waste and a strategy to minimize environmental impact, including job and income opportunities, with economic 
gains for the municipality. This is a major challenge for ELTs management because good waste collection outcomes depend on underlying socioeconomic factors such as the level of society's awareness of environmental education, the clarity of benefits, economic and fiscal incentives and the tangible gains of public policy in relation to the municipal solid waste management plan. All of these actions have a strong impact on the SEMw.

Not all materials that are available in the aftermarket will be consumed directly due to inherent uncertainties in SEF (local gross domestic product, municipal sanitary conditions, municipal policy, aggregate consumption and local culture). Moreover, the integration of DMF and RMF according to hypothesis $\mathrm{H} 4$, described in Table 4, represented by CLSC, is a CE challenge, to minimize environmental impacts caused by the incorrect disposal of the RMF of ELTs.

Regarding social aspects, considering the different perceptions of the participants of the research sample, SDF do not exert a direct influence on the SEMw. Increasing per capita income (SDF-3), education (SDF_4) and population density (SDF_5) exert a slight and direct influence on the SEF as shown in the structural model diagram in Figure 4. This phenomenon can be explained by the hypothesis of the EKC, which is also adopted to measure the relationship between per capita growth and environmental pollution.

The general public survey is the major method of the study so the results besides describe the correlations in public perception of the model constructs and their real interdependence. In addition, the perception of the target audience may change in other field research, depending on the socioeconomic situation or different socioeconomic structures. However, the initial assumptions of sample planning must be reassessed to replicate the proposed method.

\section{Recommendations and Future Work}

The following recommendations apply as an extension of the work developed:

(a) Expansion of the proposed methodology through its application in another city of the same size involving other types of solid waste (glass, plaster and other construction waste) in order to assess the socioeconomic metabolism of these residues from a social perception.

(b) Application of the results obtained in this work in the planning and management of urban solid waste in the analyzed city (Section 5 , model construction as a tool for waste management), as a support tool for public policies that allow to understand, control and manage the effects of generation of waste at source, regardless of socioeconomic features.

The main limitation verified in the proposed methodology refers to obtaining the answers to the questionnaire applied to the tire manufacturers' public, according to the sampling plan. In general, as also verified in the literature [28], the inherent competition in the market and the need for secrecy in tire production processes contribute to the fact that manufacturers do not provide information related to technical issues, especially those associated with reverse logistics. In this case, the existence of partner companies co-responsible for the management of ELTs also represents a difficulty for the acquisition of information.

Author Contributions: The author E.S.B. participated directly in the collection of information (questionnaire) and in the modeling through structural equations. The authors C.H.d.O.F. and J.L.M.R. participated in the analysis of the model and discussion of the results. The authors S.Á.F. and A.M.S.F. contributed through the selection of criteria and statistical tools for the analysis and discussion of the results. All authors have read and agreed to the published version of the manuscript.

Funding: This research received no external funding.

Acknowledgments: The authors acknowledge the Federal Agency for Support and Evaluation of Graduate Education (Coordenação de Aperfeiçoamento de Pessoal de Nível Superior, CAPES-BRAZIL), the National Council for Scientific and Technological Development (Conselho Nacional de Desenvolvimento Científico e Tecnológico, CNPq-BRAZIL) Productivity of Research Funds Processes 301105/2016-2 and 301999/2015-5, for their financial support, and the municipality of Vitória da Conquista da Bahia (Brazil) for providing data and information necessary to carry out this work.

Conflicts of Interest: The authors declare no conflict of interest. 


\section{Appendix A}

Table A1. Questionnaire (Constructs and Indicators) with Likert scale 1 to 5.

\begin{tabular}{|c|c|}
\hline Item & Construct-Socioeconomic Metabolism of Waste (SEMw) \\
\hline \multicolumn{2}{|c|}{$\begin{array}{c}\text { What is the importance }(\ldots) \text { to evaluate the socioeconomic metabolism of SEMw: }(1=\text { low } \\
\text { importance, } 5=\text { high importance })\end{array}$} \\
\hline SEMw_1 & of the ENVIRONMENTAL COST \\
\hline SEMw_2 & of MATERIAL FLOW ANALYSIS (MFA) \\
\hline SEMw_3 & of CIRCULAR ECONOMY conditions \\
\hline SEMw_4 & of the ECONOMIC VALUE of recycled materials \\
\hline SEMw_5 & of LIFE CYCLE analysis (LCA) \\
\hline SEMw_6 & of accounting for MASS BALANCE \\
\hline SEMw_7 & of INPUT AND OUTPUT ANALYSIS (IOA) \\
\hline SEMw_8 & of METABOLIC RATE WASTE MEASUREMENT \\
\hline ITEM & CONSTRUCT_DIRECT MATERIAL FLOWS (DMF) \\
\hline \multicolumn{2}{|c|}{$\begin{array}{l}\text { What is the importance }(\ldots) \text { in evaluating direct material flows in SEMw? } \\
\qquad(1=\text { low importance, } 5=\text { high importance })\end{array}$} \\
\hline DMF_1 & of the wholesaler new tire SUPPLIER NETWORK ... \\
\hline DMF_2 & of the retailer SUPPLIER NETWORK for new tires. \\
\hline DMF_3 & of tire DEMAND ... \\
\hline DMF_4 & of tire REQUESTS \\
\hline DMF_5 & of the LOCATION OF TIRE SUPPLIERS \\
\hline DMF_6 & of the REGULATION that establishes conditioning factors \\
\hline DMF_7 & of tire MARKETING \\
\hline ITEM & CONSTRUCT_REVERSE MATERIAL FLOWS (DMF) \\
\hline \multicolumn{2}{|c|}{$\begin{array}{l}\text { What is the importance }(\ldots) \text { to evaluate the reverse material flows in SEMw? } \\
\qquad(1=\text { low importance, } 5=\text { high importance })\end{array}$} \\
\hline RMF_1 & ELT COLLECTION in the city \\
\hline RMF_2 & of URBAN PLANNING of the city regarding the collection of ELTs \\
\hline RMF_3 & Accumulation of End-of-Life Tires (ELTs) \\
\hline RMF_4 & EXTERNALITIES (imports) of ELTs \\
\hline RMF_5 & of the final destination of ELTs \\
\hline RMF_6 & of ELTS RECYCLING \\
\hline RMF_7 & of ELTs retreading ... \\
\hline RMF_8 & WASTE FLOW PREDICTIONS (ELTS) \\
\hline RMF_9 & of WASTE MANAGEMENT in the city \\
\hline RMF_10 & of the training of the urban cleaning team \\
\hline ITEM & CONSTRUCT—SOCIO-ECONOMIC ENVIRONMENT (SEE) \\
\hline \multicolumn{2}{|c|}{$\begin{array}{l}\text { What is the importance }(\ldots) \text { in the evaluation of SEMw? } \\
\qquad(1=\text { low importance, } 5=\text { high importance })\end{array}$} \\
\hline SEF_1 & of the municipal INVESTMENT \\
\hline SEF_2 & of municipal POLICY in cleaning the city \\
\hline SEF_3 & of BASIC SANITATION in cleaning the city \\
\hline SEF_4 & of GDP (aggregate income) of tire economy \\
\hline SEF_5 & of tire and ELT consumption \\
\hline SEF_6 & of the local CULTURE \\
\hline ITEM & CONSTRUCT_SOCIODEMOGRAPHIC FACTORS (SDF) \\
\hline \multicolumn{2}{|c|}{$\begin{array}{l}\text { What is the importance }(\ldots) \text { in the evaluation of SEMw? } \\
\qquad(1=\text { low importance, } 5=\text { high importance })\end{array}$} \\
\hline SDF_1 & of FAMILY COMPOSITION \\
\hline SDF_2 & of the PROFESSIONAL ACTIVITY of the population \\
\hline SDF_3 & of per capita income of the population. \\
\hline SDF_4 & of the level of education of society \\
\hline SDF_5 & of POPULATIONAL DENSITY. \\
\hline SDF_6 & of the AGE of society \\
\hline SDF_7 & of URBAN SPACE \\
\hline
\end{tabular}




\section{References}

1. Schröder, P.; Vergragt, P.; Brown, H.S.; Dendler, L.; Gorenflo, N.; Matus, K.; Quist, J.; Rupprecht, C.D.; Tukker, A.; Wennersten, R. Advancing sustainable consumption and production in cities-A transdisciplinary research and stakeholder engagement framework to address consumption-based emissions and impacts. J. Clean. Prod. 2019, 213, 114-125. [CrossRef]

2. Witt, U. The evolution of consumption and its welfare effects. J. Evol. Econ. 2017, 27, 273-293. [CrossRef] [PubMed]

3. Jaiswal, A.; Kumar, S. Waste Legislation Across the Globe: An Overview. In Current Developments in Biotechnology and Bioengineering; Elsevier: Amsterdam, The Netherlands, 2019; pp. 11-30.

4. Ghinea, C.; Drăgoi, E.N.; Comăniţă, E.D.; Gavrilescu, M.; Câmpean, T.; Curteanu, S.I.L.V.I.A.; Gavrilescu, M. Forecasting municipal solid waste generation using prognostic tools and regression analysis. J. Environ. Manag. 2016, 182, 80-93. [CrossRef]

5. Kallel, A.; Serbaji, M.M.; Zairi, M. Using GIS-Based tools for the optimization of solid waste collection and transport: Case study of Sfax City, Tunisia. J. Eng. 2016, 2016. [CrossRef]

6. Srivastava, S.; Jamwal, D.S. Determinants of awareness and disposal habits of households for effective municipal solid waste management. J. Glob. Bus. Adv. 2019, 12, 405-428. [CrossRef]

7. Zouboulis, A.I.; Peleka, E.N. “Cycle closure” in waste management: Tools, procedures and examples. Glob. Nest J. 2019, 21, 1-6.

8. Adipah, S. Challenges and Improvement Opportunities for Accra City MSWM System. J. Environ. Sci. 2019, 3, 133-146. [CrossRef]

9. Cocarta, D.M.; Rada, E.C.; Ragazzi, M.; Badea, A.; Apostol, T. A contribution for a correct vision of health impact from municipal solid waste treatments. Environ. Technol. 2009, 30, 963-968. [CrossRef]

10. Ferronato, N.; Torretta, V.; Ragazzi, M.; Rada, E.C. Waste mismanagement in developing countries: A case study of environmental contamination. UPB Sci. Bull. 2017, 79, 185-196.

11. Van Fan, Y.; Klemeš, J.J.; Walmsley, T.G.; Bertók, B. Implementing Circular Economy in municipal solid waste treatment system using P-graph. Sci. Total Environ. 2020, 701, 134652. [CrossRef]

12. Ziraba, A.K.; Haregu, T.N.; Mberu, B. A review and framework for understanding the potential impact of poor solid waste management on health in developing countries. Arch. Public Health 2016, 74, 55. [CrossRef]

13. Mohee, R.; Simelane, T. Future Directions of Municipal Solid Waste Management in Africa; Africa Institute of South Africa: Pretoria, South Africa, 2015.

14. Aderemi, A.O.; Oriaku, A.V.; Adewumi, G.A.; Otitoloju, A.A. Technology. Assessment of groundwater contamination by leachate near a municipal solid waste landfill. J. Environ. Sci. Technol. 2011, 5, 933-940.

15. Han, Z.; Ma, H.; Shi, G.; He, L.; Wei, L.; Shi, Q. A review of groundwater contamination near municipal solid waste landfill sites in China. Sci. Total Environ. 2016, 569, 1255-1264. [CrossRef]

16. Chen, G.; Sun, Y.; Xu, Z.; Shan, X.; Chen, Z. Assessment of Shallow Groundwater Contamination Resulting from a Municipal Solid Waste Landfill-A Case Study in Lianyungang, China. Water 2019, 11, 2496. [CrossRef]

17. Yousefloo, A.; Babazadeh, R. Designing an integrated municipal solid waste management network: A case study. J. Clean. Prod. 2020, 244, 118824. [CrossRef]

18. Cecchin, A.; Lamour, M.; Joseph Maks Davis, M.; Jácome Polit, D. End-of-life product management as a resilience driver for developing countries: A policy experiment for used tires in Ecuador. J. Ind. Ecol. 2019, 23, 1292-1310. [CrossRef]

19. Ishola Felix, A.; Ajayi Oluseyi, O.; Oyawale, F.; Akinlabi, S.A. Sustainable End-of-Life Tyre (EOLT) Management for Developing Countries-A Review. In Proceedings of the International Conference on Industrial Engineering and Operations Management, Pretoria/Johannesburg, South Africa, 29 October-1 November 2018.

20. Torretta, V.; Rada, E.C.; Ragazzi, M.; Trulli, E.; Istrate, I.A.; Cioca, L.I. Treatment and disposal of tyres: Two EU approaches. A review. Waste Manag. 2015, 45, 152-160. [CrossRef]

21. Rada, E.C.; Ragazzi, M.; Dal Maschio, R.; Ischia, M.; Panaitescu, V.N. Politehnica University of Bucharest, Series D, Mechanical Engineering. Energy recovery from tyres waste through thermal option. Sci. Bull. Politeh. Univ. Buchar. Ser. D Mech. Eng. 2012, 74, 201-210. 
22. Stanojević, D.D.; Rajković, M.B.; Tošković, D.V. Management of used tires, accomplishments in the world, and situation in Serbia. Hemijska Industrija 2011, 65, 727-738. [CrossRef]

23. Sienkiewicz, M.; Kucinska-Lipka, J.; Janik, H.; Balas, A. Progress in used tyres management in the European Union: A review. Waste Manag. 2012, 32, 1742-1751. [CrossRef]

24. Aliabdo, A.A.; Abd Elmoaty, A.E.M.; AbdElbaset, M.M. Utilization of waste rubber in non-structural applications. Constr. Build. Mater. 2015, 91, 195-207. [CrossRef]

25. Ribeiro Filho, S.L.M.; Oliveira, P.R.; Panzera, T.H.; Scarpa, F. Impact of hybrid composites based on rubber tyres particles and sugarcane bagasse fibres. Compos. Part B Eng. 2019, 159, 157-164. [CrossRef]

26. Perondi, D.; Marcolin, P.; Biondo, L.; de Souza, G.; de Matos, E.F.; Dettmer, A.; Godinho, M.; Vilela, A.C.F. Co-Pirólise De Resíduos De Pneus E Resina Polimérica Presente Na Areia De Fundição. In Proceedings of the 8th International Bioenergy Congress, Sao Paulo, Brazil, 5-7 November 2013.

27. Marchiori, H. Estudo de Viabilidade da Aplicação de Pneus Como Combustível na Geração de Energia Elétrica. Available online: http://sites.poli.usp.br/d/pme2600/2007/Artigos/Art_TCC_059_2007.pdf (accessed on 12 January 2020).

28. Mmereki, D.; Machola, B.; Mokokwe, K. Status of waste tires and management practice in Botswana. J. Air Waste Manag. Assoc. 2019, 69, 1230-1246. [CrossRef]

29. Fischer-Kowalski, M. Regional and National Material Flow Accounting: From Paradigm to Practice of Sustainability; Science Centre North Rhine-Westphalia: Wuppertal, Germany, 1997.

30. Hertz, T.; Schlüter, M. The SES-framework as boundary object to address theory orientation in social-ecological system research: The SES-TheOr approach. Ecol. Econ. 2015, 116, 12-24. [CrossRef]

31. Cammack, R.; Atwood, T.; Campbell, P.; Parish, H.; Smith, A.; Vella, F.; Stirling, J. Metabolism; Oxford Dictionary of Biochemistry and Molecular Biology; Oxford University Press: Oxford, UK, 2008.

32. Ayres, R.U.; Simonis, U.E. Industrial Metabolism: Restructuring for Sustainable Development; United Nations University Press: New York, NY, USA, 1994.

33. Baccini, P.; Brunner, P.H. Metabolism of the Anthroposphere; Springer: Berlin/Heidelberg, Germany, 1991.

34. Baccini, P.; Brunner, P.H. Metabolism of the Anthroposphere: Analysis, Evaluation, Design; MIT Press: Cambridge, MA, USA, 2012.

35. Fischer-Kowalski, M. Society's metabolism: The intellectual history of materials flow analysis, Part I, 1860-1970. J. Ind. Ecol. 1998, 2, 61-78. [CrossRef]

36. Wolman, A. The metabolism of cities. Sci. Am. 1965, 213, 178-193. [CrossRef]

37. Pauliuk, S.; Hertwich, E.G. Prospective models of society's future metabolism: What industrial ecology has to contribute. In Taking Stock of Industrial Ecology; Springer: Cham, Germany, 2016; pp. 21-43.

38. Allesch, A.; Brunner, P.H. Material flow analysis as a decision support tool for waste management: A literature review. J. Ind. Ecol. 2015, 19, 753-764. [CrossRef]

39. Pauliuk, S.; Majeau-Bettez, G.; Müller, D.B. A general system structure and accounting framework for socioeconomic metabolism. J. Ind. Ecol. 2015, 19, 728-741. [CrossRef]

40. Fischer-Kowalski, M.; Haberl, H. El metabolismo socieconómico. Ecología Política 2000, 19, $21-33$.

41. Pauliuk, S.; Müller, D.B. The role of in-use stocks in the social metabolism and in climate change mitigation. Glob. Environ. Chang. 2014, 24, 132-142. [CrossRef]

42. Fischer-Kowalski, M.; Haberl, H. Socioecological Transitions and Global Change: Trajectories of Social Metabolism and Land Use; Edward Elgar: Cheltenham, UK; Northampton, MA, USA, 2007.

43. Fischer-Kowalski, M.; Weisz, H. Society as hybrid between material and symbolic realms: Toward a theoretical framework of society-nature interaction. Adv. Hum. Ecol. 1999, 8, 215-252.

44. Kennedy, C.; Cuddihy, J.; Engel-Yan, J. The changing metabolism of cities. J. Ind. Ecol. 2007, 11, 43-59. [CrossRef]

45. Newell, J.P.; Cousins, J.J. The boundaries of urban metabolism: Towards a political-industrial ecology. Prog. Hum. Geogr. 2015, 39, 702-728. [CrossRef]

46. Wang, Y.; Chen, P.-C.; Ma, H.-W.; Cheng, K.-L.; Chang, C.-Y. Socio-economic metabolism of urban construction materials: A case study of the Taipei metropolitan area. Resour. Conserv. Recycl. 2018, 128, 563-571. [CrossRef]

47. Li, H.; Kwan, M.-P. Advancing analytical methods for urban metabolism studies. Resour. Conserv. Recycl. 2018, 132, 239-245. [CrossRef]

48. Zhang, Y.; Yang, Z.; Yu, X. Urban metabolism: A review of current knowledge and directions for future study. Environ. Sci. Technol. 2015, 49, 11247-11263. [CrossRef] 
49. Dai, T.; Wang, W. The characteristics and trends of socioeconomic metabolism in China. J. Ind. Ecol. 2018, 22, 1228-1240. [CrossRef]

50. Fami, H.S.; Aramyan, L.H.; Sijtsema, S.J.; Alambaigi, A. Determinants of household food waste behavior in Tehran city: A structural model. Resour. Conserv. Recycl. 2019, 143, 154-166. [CrossRef]

51. Srun, P.; Kurisu, K. Internal and External Influential Factors on Waste Disposal Behavior in Public Open Spaces in Phnom Penh, Cambodia. Sustainability 2019, 11, 1518. [CrossRef]

52. Ma, B.; Li, X.; Jiang, Z.; Jiang, J. Recycle more, waste more? When recycling efforts increase resource consumption. J. Clean. Prod. 2019, 206, 870-877. [CrossRef]

53. Arı, E.; Yilmaz, V. A proposed structural model for housewives' recycling behavior: A case study from Turkey. Ecol. Econ. 2016, 129, 132-142. [CrossRef]

54. Lu, M.; Wei, M. Analysis of the Factors Affected Construction Waste's Management in Structure Equation Model. Advanced Materials Research. Adv. Mater. Res. Trans. Tech. Publ. Ltd 2014, 878, 315-321. [CrossRef]

55. Kannan, D.; Diabat, A.; Shankar, K.M. Analyzing the drivers of end-of-life tire management using interpretive structural modeling (ISM). Int. J. Adv. Manuf. Technol. 2014, 72, 1603-1614. [CrossRef]

56. Beigl, P.; Lebersorger, S.; Salhofer, S. Modelling municipal solid waste generation: A review. Waste Manag. 2008, 28, 200-214. [CrossRef] [PubMed]

57. Durdyev, S.; Ihtiyar, A.; Banaitis, A.; Thurnell, D. The construction client satisfaction model: A PLS-SEM approach. J. Civil. Eng. Manag. 2018, 24,31-42. [CrossRef]

58. Hair, J.F., Jr.; Sarstedt, M.; Ringle, C.M.; Gudergan, S.P. Advanced Issues in Partial Least Squares Structural Equation Modeling; SAGE Publications: Newcastle upon Tyne, UK, 2017.

59. Reinartz, W.; Haenlein, M.; Henseler, J. An empirical comparison of the efficacy of covariance-based and variance-based SEM. Int. J. Res. Mark. 2009, 26, 332-344. [CrossRef]

60. Sarstedt, M.; Hair, J.F.; Ringle, C.M.; Thiele, K.O.; Gudergan, S.P. Estimation issues with PLS and CBSEM: Where the bias lies! J. Bus. Res. 2016, 69, 3998-4010. [CrossRef]

61. Rigdon, E.E.; Sarstedt, M.; Ringle, C.M. On comparing results from CB-SEM and PLS-SEM: Five perspectives and five recommendations. Mark. Zfp 2017, 39, 4-16. [CrossRef]

62. Streukens, S.; Leroi-Werelds, S. Bootstrapping and PLS-SEM: A step-by-step guide to get more out of your bootstrap results. Eur. Manag. J. 2016, 34, 618-632. [CrossRef]

63. Henseler, J.; Ringle, C.M.; Sinkovics, R.R. The use of partial least squares path modeling in international marketing. In New Challenges to International Marketing; Emerald Group Publishing Limited: England, UK, 2009; pp. 277-319.

64. Davari, A.; Rezazadeh, A. Structural equation modeling with PLS. Tehran Jahad Univ. 2013, 215, 224.

65. Krausmann, F.; Gingrich, S.; Nourbakhch-Sabet, R. The metabolic transition in Japan: A material flow account for the period from 1878 to 2005. J. Ind. Ecol. 2011, 15, 877-892. [CrossRef]

66. Fischer-Kowalski, M.; Krausmann, F.; Giljum, S.; Lutter, S.; Mayer, A.; Bringezu, S.; Moriguchi, Y.; Schütz, H.; Schandl, H.; Weisz, H. Methodology and indicators of economy-wide material flow accounting. J. Ind. Ecol. 2011, 15, 855-876. [CrossRef]

67. Fischer-Kowalski, M.; Krausmann, F.; Pallua, I. A sociometabolic reading of the Anthropocene: Modes of subsistence, population size and human impact on Earth. Anthr. Rev. 2014, 1, 8-33. [CrossRef]

68. Krausmann, F.; Lauk, C.; Haas, W.; Wiedenhofer, D. From resource extraction to outflows of wastes and emissions: The socioeconomic metabolism of the global economy, 1900-2015. Glob. Environ. Chang. 2018, 52, 131-140. [CrossRef]

69. CONAMA. Resolução 416 de 30 de Setembro de 2009. Available online: http://www2.mma.gov.br/port/ conama/legiabre.cfm?codlegi=616 (accessed on 12 January 2020).

70. Shulman, V.L. Tire Recycling; Smithers Rapra Press: Shropshire, UK, 1999.

71. Gupt, Y.; Sahay, S. Review of extended producer responsibility: A case study approach. Waste Manag. Res. 2015, 33, 595-611. [CrossRef]

72. Fagundes, L.D.; Amorim, E.S.; da Silva Lima, R. Action research in reverse logistics for end-of-life tire recycling. Syst. Pract. Action Res. 2017, 30, 553-568. [CrossRef]

73. Schultmann, F.; Zumkeller, M.; Rentz, O. Modeling reverse logistic tasks within closed-loop supply chains: An example from the automotive industry. Eur. J. Oper. Res. 2006, 171, 1033-1050. [CrossRef]

74. Govindan, K.; Soleimani, H.; Kannan, D. Reverse logistics and closed-loop supply chain: A comprehensive review to explore the future. Eur. J. Oper. Res. 2015, 240, 603-626. [CrossRef] 
75. Agrawal, S.; Singh, R.K.; Murtaza, Q. A literature review and perspectives in reverse logistics. Resour. Conserv. Recycl. 2015, 97, 76-92. [CrossRef]

76. Adzawla, W.; Tahidu, A.; Mustapha, S.; Azumah, S.B. Do socioeconomic factors influence households' solid waste disposal systems? Evidence from Ghana. Waste Manag. Res. 2019, 37, 51-57. [CrossRef]

77. Rybova, K. Do Sociodemographic Characteristics in Waste Management Matter? Case Study of Recyclable Generation in the Czech Republic. Sustainability 2019, 11, 2030. [CrossRef]

78. Hair, J.F., Jr.; Sarstedt, M.; Hopkins, L.; Kuppelwieser, V.G. Partial least squares structural equation modeling (PLS-SEM) An emerging tool in business research. Eur. Bus. Rev. 2014, 26, 106-121. [CrossRef]

79. Lu, J.-W.; Chang, N.-B.; Zhu, F.; Hai, J.; Liao, L. Smart and green urban solid waste collection system for differentiated collection with integrated sensor networks. In Proceedings of the Networking, Sensing and Control (ICNSC), 2018 IEEE 15th International Conference on, Zhuhai, China, 27-29 March 2018; pp. 1-5.

80. Wisner, J.D. A structural equation model of supply chain management strategies and firm performance. $J$. Bus. Logist. 2003, 24, 1-26. [CrossRef]

81. Cohen, J. Statistical Power Analysis for the Behavioral Sciences; Routledge: Abingdon, UK, 2013.

82. Hair, J.F.; Ringle, C.M.; Gudergan, S.P.; Fischer, A.; Nitzl, C.; Menictas, C. Partial least squares structural equation modeling-based discrete choice modeling: An illustration in modeling retailer choice. Bus. Res. 2019, 12, 115-142. [CrossRef]

83. Davison, A.C.; Hinkley, D.V. Bootstrap Methods and Their Application; Cambridge University press: Cambridge, UK, 1997.

84. Wong, K.K.-K. Mastering Partial Least Squares Structural Equation Modeling (PLS-SEM) with Smartpls in 38 Hours; iUniverse: Bloomington, IN, USA, 2019.

85. Hair, J.F., Jr.; Hult, G.T.M.; Ringle, C.; Sarstedt, M. A Primer on Partial Least Squares Structural Equation Modeling (PLS-SEM); Sage publications: New York, NY, USA, 2016.

86. Chin, W.W. The partial least squares approach to structural equation modeling. Mod. Methods Bus. Res. 1998, 295, 295-336.

87. Fornell, C.; Larcker, D.F. Structural Equation Models with Unobservable Variables and Measurement Error: Algebra and Statistics; SAGE Publications Sage CA: Los Angeles, CA, USA, 1981.

88. Hair, J.F.; Risher, J.J.; Sarstedt, M.; Ringle, C.M. When to use and how to report the results of PLS-SEM. Eur. Bus. Rev. 2019, 31, 2-24. [CrossRef]

89. Dijkstra, T.K.; Henseler, J. Consistent partial least squares path modeling. MIS Q. 2015, 39, 297-316. [CrossRef]

90. Sarstedt, M.; Ringle, C.M.; Henseler, J.; Hair, J.F. On the emancipation of PLS-SEM: A commentary on Rigdon (2012). Long Range Plan. 2014, 47, 154-160. [CrossRef]

91. Cohen, J. Statistical Power Analysis for the Behaviors Science, 2nd ed.; Laurence Erlbaum Associates: Hillsdale, MN, USA, 1988.

92. Pedram, A.; Yusoff, N.B.; Udoncy, O.E.; Mahat, A.B.; Pedram, P.; Babalola, A. Integrated forward and reverse supply chain: A tire case study. Waste Manag. 2017, 60,460-470. [CrossRef]

93. Antoniou, N.; Zabaniotou, A. Re-designing a viable ELTs depolymerization in circular economy: Pyrolysis prototype demonstration at TRL 7, with energy optimization and carbonaceous materials production. J. Clean. Prod. 2018, 174, 74-86. [CrossRef]

94. Maderuelo-Sanz, R.; Nadal-Gisbert, A.V.; Crespo-Amorós, J.E.; Parres-García, F. A novel sound absorber with recycled fibers coming from end of life tires (ELTs). Appl. Acoust. 2012, 73, 402-408. [CrossRef]

95. Pehlken, A.; Müller, D.H. Using information of the separation process of recycling scrap tires for process modelling. Resour. Conserv. Recycl. 2009, 54, 140-148. [CrossRef]

96. Haberl, H.; Steinberger, J.K.; Plutzar, C.; Erb, K.H.; Gaube, V.; Gingrich, S.; Krausmann, F. Natural and socioeconomic determinants of the embodied human appropriation of net primary production and its relation to other resource use indicators. Ecol. Indic. 2012, 23, 222-231. [CrossRef] [PubMed]

97. Shah, K.U.; Niles, K.; Ali, S.H.; Surroop, D.; Jaggeshar, D. Plastics Waste Metabolism in a Petro-Island State: Towards Solving a "Wicked Problem" in Trinidad and Tobago. Sustainability 2019, 11, 6580. [CrossRef]

98. Marega, F. The Retreaded Tyres Case in WTO: An Important Multilateral Achievement by Brazil. In The WTO Dispute Settlement Mechanism; Springer: Berlin/Heidelberg, Germany, 2019; pp. 321-338.

99. IBGE. Tire sales in Brazil from 2010 to 2015. In Diretoria de Pesquisas, Coordenação de Contas Nacionais; Instituto Brasileiro de Geografia e Estatística: Rio de Janeiro, Brazil, 2020. 
100. Mazzanti, M.; Montini, A.; Zoboli, R. Municipal waste generation and socioeconomic drivers: Evidence from comparing Northern and Southern Italy. J. Environ. Dev. 2008, 17, 51-69. [CrossRef]

101. Lonca, G.; Muggéo, R.; Imbeault-Tétreault, H.; Bernard, S.; Margni, M. Does material circularity rhyme with environmental efficiency? Case studies on used tires. J. Clean. Prod. 2018, 183, 424-435. [CrossRef]

102. Megiddo, T. Beyond Fragmentation: On International Law's Integrationist Forces. Yale J. Int. Law 2019, $44,4$.

103. Krausmann, F.; Wiedenhofer, D.; Lauk, C.; Haas, W.; Tanikawa, H.; Fishman, T.; Miatto, A.; Schandl, H.; Haberl, H. Global socioeconomic material stocks rise 23-fold over the 20th century and require half of annual resource use. Proc. Natl. Acad. Sci. USA 2017, 114, 1880-1885. [CrossRef]

104. Pauliuk, S.; Wood, R.; Hertwich, E.G. Dynamic models of fixed capital stocks and their application in industrial ecology. J. Ind. Ecol. 2015, 19, 104-116. [CrossRef]

105. Fishman, T.; Schandl, H.; Tanikawa, H. The socio-economic drivers of material stock accumulation in Japan's prefectures. Ecol. Econ. 2015, 113, 76-84. [CrossRef]

106. Mazzanti, M.; Zoboli, R. Waste generation, waste disposal and policy effectiveness: Evidence on decoupling from the European Union. Resour. Conserv. Recycl. 2008, 52, 1221-1234. [CrossRef]

107. Dombi, M.; Karcagi-Kováts, A.; Tóth-Szita, K.; Kuti, I. The structure of socio-economic metabolism and its drivers on household level in Hungary. J. Clean. Prod. 2018, 172, 758-767. [CrossRef]

108. Strobel, M.; Redmann, C. Flow cost accounting, an accounting approach based on the actual flows of materials. In Environmental Management Accounting: Informational and Institutional Developments; Springer: Berlin/Heidelberg, Germany, 2002; pp. 67-82.

109. Cole, M.A.; Rayner, A.J.; Bates, J.M. The environmental Kuznets curve: An empirical analysis. Environ. Dev. Econ. 1997, 2, 401-416. [CrossRef]

110. Chang, N.-B. Economic and policy instrument analyses in support of the scrap tire recycling program in Taiwan. J. Environ. Manag. 2008, 86, 435-450. [CrossRef] [PubMed]

111. Ferrer, G. The economics of tire remanufacturing. Resour. Conserv. Recycl. 1997, 19, 221-255. [CrossRef]

112. Govindan, K.; Palaniappan, M.; Zhu, Q.; Kannan, D. Analysis of third party reverse logistics provider using interpretive structural modeling. Int. J. Prod. Econ. 2012, 140, 204-211. [CrossRef]

113. Ramayah, T.; Lee, J.W.C.; Lim, S. Sustaining the environment through recycling: An empirical study. J. Environ. Manag. 2012, 102, 141-147. [CrossRef]

114. Barr, S. Household Waste in Social Perspective: Values, Attitudes, Situation and Behaviour; Routledge: Abingdon, UK, 2017.

115. Haas, W.; Krausmann, F.; Wiedenhofer, D.; Heinz, M. How circular is the global economy?: An assessment of material flows, waste production, and recycling in the European Union and the world in 2005. J. Ind. Ecol. 2015, 19, 765-777. [CrossRef]

116. Swami, V.; Chamorro-Premuzic, T.; Snelgar, R.; Furnham, A. Personality, individual differences, and demographic antecedents of self-reported household waste management behaviours. J. Environ. Psychol. 2011, 31, 21-26. [CrossRef]

117. Chang, N.-B.; Pires, A.; Martinho, G. Empowering systems analysis for solid waste management: Challenges, trends, and perspectives. Crit. Rev. Environ. Sci. Technol. 2011, 41, 1449-1530. [CrossRef]

118. Rybova, K.; Burcin, B.; Slavik, J. Spatial and non-spatial analysis of socio-demographic aspects influencing municipal solid waste generation in the Czech Republic. Detritus 2018, 1, 3.

119. Xu, L.; Lin, T.; Xu, Y.; Xiao, L.; Ye, Z.; Cui, S. Path analysis of factors influencing household solid waste generation: A case study of Xiamen Island, China. J. Mater. Cycles Waste Manag. 2016, 18, 377-384. [CrossRef]

120. Kannangara, M.; Dua, R.; Ahmadi, L.; Bensebaa, F. Modeling and prediction of regional municipal solid waste generation and diversion in Canada using machine learning approaches. Waste Manag. 2018, 74, 3-15. [CrossRef]

121. Bach, H.; Mild, A.; Natter, M.; Weber, A. Combining socio-demographic and logistic factors to explain the generation and collection of waste paper. Resour. Conserv. Recycl. 2004, 41, 65-73. [CrossRef]

122. Azevedo, L.P.; Araújo, F.G.D.S.; Lagarinhos, C.A.F.; Tenório, J.A.S.; Espinosa, D.C. Resource Recovery From E-waste for Environmental Sustainability: A Case Study in Brazil. In Electronic Waste Management and Treatment Technology; Elsevier: Amsterdam, The Netherlands, 2019; pp. 175-200.

123. Madden, B.; Florin, N.; Mohr, S.; Giurco, D. Using the waste Kuznet's curve to explore regional variation in the decoupling of waste generation and socioeconomic indicators. Resour. Conserv. Recycl. 2019, 149, 674-686. [CrossRef] 
124. Riediger, N.D.; Shooshtari, S.; Moghadasian, M.H. The influence of sociodemographic factors on patterns of fruit and vegetable consumption in Canadian adolescents. J. Am. Diet. Assoc. 2007, 107, 1511-1518. [CrossRef]

125. Binder, C.R. From material flow analysis to material flow management Part I: Social sciences modeling approaches coupled to MFA. J. Clean. Prod. 2007, 15, 1596-1604. [CrossRef]

126. Gomes, T.S.; Neto, G.R.; de Salles, A.C.N.; Visconte, L.L.Y.; Pacheco, E.B.A.V. End-of-Life Tire Destination from a Life Cycle Assessment Perspective. In New Frontiers on Life Cycle Assessment-Theory and Application; IntechOpen: London, UK, 2019.

127. Knickmeyer, D. Social factors influencing household waste separation: A literature review on good practices to improve the recycling performance of urban areas. J. Clean. Prod. 2019, 245, 118605. [CrossRef]

128. Villela, G.O.M.; Silva, F.B. A logística reversa de pneus. Rev. Vianna Sapiens 2019, 10, 17. [CrossRef]

129. Hayduk, L.A.; Littvay, L. Should researchers use single indicators, best indicators, or multiple indicators in structural equation models? BMC Med Res. Methodol. 2012, 12, 159. [CrossRef]

130. Hulland, J. Use of partial least squares (PLS) in strategic management research: A review of four recent studies. Strateg. Manag. J. 1999, 20, 195-204. [CrossRef]

131. Gefen, D.; Straub, D.; Boudreau, M.-C. Structural equation modeling and regression: Guidelines for research practice. Commun. Assoc. Inf. Syst. 2000, 4, 7. [CrossRef]

(C) 2020 by the authors. Licensee MDPI, Basel, Switzerland. This article is an open access article distributed under the terms and conditions of the Creative Commons Attribution (CC BY) license (http://creativecommons.org/licenses/by/4.0/). 